\title{
Studying time in organizational behavior
}

Citation for published version (APA):

Roe, R. A. (2005). Studying time in organizational behavior. METEOR, Maastricht University School of Business and Economics. METEOR Research Memorandum No. 046 https://doi.org/10.26481/umamet.2005046

Document status and date:

Published: 01/01/2005

DOI:

10.26481/umamet.2005046

Document Version:

Publisher's PDF, also known as Version of record

\section{Please check the document version of this publication:}

- A submitted manuscript is the version of the article upon submission and before peer-review. There can be important differences between the submitted version and the official published version of record.

People interested in the research are advised to contact the author for the final version of the publication, or visit the DOI to the publisher's website.

- The final author version and the galley proof are versions of the publication after peer review.

- The final published version features the final layout of the paper including the volume, issue and page numbers.

Link to publication

\footnotetext{
General rights rights.

- You may freely distribute the URL identifying the publication in the public portal. please follow below link for the End User Agreement:

www.umlib.nl/taverne-license

Take down policy

If you believe that this document breaches copyright please contact us at:

repository@maastrichtuniversity.nl

providing details and we will investigate your claim.
}

Copyright and moral rights for the publications made accessible in the public portal are retained by the authors and/or other copyright owners and it is a condition of accessing publications that users recognise and abide by the legal requirements associated with these

- Users may download and print one copy of any publication from the public portal for the purpose of private study or research.

- You may not further distribute the material or use it for any profit-making activity or commercial gain

If the publication is distributed under the terms of Article $25 \mathrm{fa}$ of the Dutch Copyright Act, indicated by the "Taverne" license above, 
Running head: Studying Time in OB

\title{
Studying time in organizational behavior
}

\author{
Robert A Roe \\ Universiteit Maastricht \\ Maastricht, The Netherlands \\ UNPUBLISHED MANUSCRIPT - MARCH 2005 \\ DON'T QUOTE WITHOUT PERMISSION
}

Address correspondence to:

Prof.dr. R.A. Roe

Universiteit Maastricht

Faculty of Economics and Business Administration

P.O. Box 616

6200 MD Maastricht

The Netherlands

Phone: +31 433884985

Fax: $\quad+31433884893$

E-mail: r.roe@os.unimaas.nl 


\title{
Studying time in organizational behavior
}

\author{
Abstract \\ This article builds on the call of various authors (e.g. George \& Jones, 2000; Mitchell \& James, \\ 2001; Rousseau \& Fried, 2001) for a better representation of time in theory-building and \\ research in organizational behavior (OB). It proposes a radical temporalist approach to the study \\ of $\mathrm{OB}$ which combines a new way of conceptualizing and formulating research questions with an \\ alternative methodology for empirical research. Abandoning the static notion of 'variable' the \\ focus is placed on inherently dynamic 'temporal phenomena'. On the basis of a generic model \\ which assumes phenomena to be temporally bounded, an analytical scheme is proposed which \\ relates the onset, duration and dynamics of phenomenon $\mathrm{A}$ to those of phenomenon $\mathrm{B}$. In this \\ way, nine prototypical problem types are defined, all of which center around time. A research \\ strategy is proposed which involves three major steps, i.e. (1) temporal modeling of OB \\ phenomena, (2) the investigation of temporal relationships, and (3) the assessment of constancy \\ and variety over longer time periods. After discussing some general methodological issues \\ (related to time scale, time frame, time grid, observation/recording, and measurement) a number \\ of methods for performing these three types of research are reviewed. They include: descriptive \\ modeling, random coefficient modeling, latent growth modeling, event history analysis, time \\ series analysis, analysis of variance, and multiple regression analysis. Finally, limitations of the \\ radical temporalist approach and future challenges are discussed.
}




\section{Studying time in organizational behavior}

As is true for all human behavior time is an inherent attribute of people's behavior in organizational settings. Everything people do, from the moment they enter an organization till they leave, that is, performing work tasks, communicating, fulfilling leadership roles, handling conflicts etc., extends in time (Bluedorn, 2002). Therefore, it would be impossible to define these behaviors without reference to time. Moreover, for people at work temporal facets are highly visible and important. Managers are typically preoccupied with deadlines, lead times, growth rates, change trajectories, etc. and they are heavily engaged in planning and monitoring change and performance. For employees time is manifest in working hours, work schedules, time pressure, but also in learning, career transition, and organizational change. In organizations time seems to be constantly salient, everything people do is framed by the days, weeks, months and quarters of the yearly calendar (Bluedorn \& Denhardt, 1988).

In spite of this evident significance of time in the definition of organizational behavior and in the experience of organizational actors, current theories and empirical studies in the field of OB give a very limited account of time. George and Jones (2000: p. 658) state that: "Many micro- and macro-organizational theories do not adequately incorporate such a time element and, thus, unintentionally distort the phenomena they are describing". Likewise, Ployhart, Holtz \& Bliese (2002, p 455-456) note: "It is probably not an overstatement to claim, that the cumulative knowledge gained from applied psychological research gives us little insight into how people develop, behave, perform and grow over time". The lack of knowledge about the temporal aspects of $\mathrm{OB}$ and the need to incorporate time in theory-building and research has recently been addressed by several authors (Ancona, Goodman, Lawrence, \& Tushman, 2001; Bergh, 1993; Chan, 1998; Fried \& Slowik, 2004; George \& Jones, 2000; McGrath \& Tschan, 2004; Mitchell \& James, 2001; Rousseau \& Fried, 2001). They seem to agree that the field of OB is in need of new 
approaches to theorizing that give time a more prominent position and of alternative research methods that are suited for the analysis of time-based data.

This aim of this article is to propose an approach to the study of OB which brings its temporal dimensions to the foreground. We will first provide some definitions, introduce the premises of the approach, and identify key issues to be addressed. Next, we will describe the implications of the approach for theory-building, propose a research strategy and discuss research methods.

\section{A radical temporalist approach}

\section{Definitions and premises}

In order to open a truly temporal perspective on $\mathrm{OB}$ we propose to do away with the prevailing practice of defining behavior in terms of (static) variables and to conceptualize it in terms of (dynamic) phenomena instead. We define phenomena are observable events that happen to a particular object (e.g. individual, group, organization). Just like variables, they are conceived by the researcher and captured through perception or recording. The difference is that where variables refer to attributes of objects that can vary in intensity, phenomena refer to processes taking place. One might also say that variables refer to what is, phenomena to what happens. Although these two ways of conceptualizing are related to each other, there are important differences. Variables are either defined without reference to time, or with reference with a specific moment in time, whereas phenomena are defined with reference to a time interval. Moreover, variables refer to singular attributes while phenomena may include a number of attributes simultaneously. An example may clarify these points: in the study of leadership one may use the variable transformational leadership style, which refers to a singular facet of leader behavior as apparent in a given moment of time, or alternatively study the phenomenon of leadership, that is, the leader's activity, covering one or more facets (including 
"transformationality"), during a week or a month. The difference is of paramount importance for the method of study. Phenomena cannot be studied without defining a time interval and without looking at change, whereas variables can (and often are). Relationships between two phenomena require a precise specification of temporal parameters of each of them, whereas the relationship between variables can be investigated with or without temporal specifications. Thus, a focus on phenomena compels the researcher to be explicit about time and make it into a focal topic of study. The leadership example is one of many. The same argument pertains to motivation, performance, productivity, turnover, stress, innovation, OCB, team processes, etc.

Another notion to define is time. Time, however, is open to many different conceptualizations (McGrath \& Tschan, 2004; Roeckelein, 2000; Slife, 1993) and difficult to grasp in its full richness. Recognizing the philosophical intricacies of defining time, we prefer to give a heuristic definition in which time is an attribute that accounts for succession of events, open to perception and recording. Accessing time through perception or through recording, leads to two very different conceptualizations, also referred to as subjective and objective time. Throughout this article we will follow the second conceptualization and refer to time as a dimension that is open to recording and subsequently to measurement. Thus, we adopt the Newtonian notion of time as used in the physical sciences. We will come back to this distinction and some of its implications later on. Time, as we will see, is the base for a range of notions needed in the study of phenomena, such as duration, speed, growth rate, etc. We will use the term temporality to refer to the all these time-related aspects of behavior.

We start from the premise that all phenomena in $\mathrm{OB}$ can be considered to be temporally bounded and dynamic. Bounded means that they have a beginning and an end; dynamic means that the intensity of one or more attributes varies over time. One might also say that all phenomena have a 'life cycle', that is they originate at a certain moment, show a certain pattern of 
change or development over the life time, and ultimately disappear. An example is the phenomenon of 'organizational commitment', or the 'feeling committed' of an employee towards an organization. The phenomenon starts when the person starts feeling committed toward the specific organization, typically at the moment of recruitment (perhaps somewhat before or after). Commitment supposedly develops over time, with upward and downward moves. By the end of the employment period (perhaps somewhat before or after) the person feels no longer committed. Instead, commitment to another employing organization may develop. The model in Figure 1 shows the temporal features of a phenomenon. The beginning is designated as onset, the end as offset. The interval between them is referred to as duration. The term dynamics is used to refer to the pattern of intensity of the phenomenon.

\section{Here Figure 1}

What makes our approach 'radical' is that we assume that all phenomena in OB to be bounded in time, or in other words to have a life cycle. Although this is an unusual assumption, it seems to make sense since all OB phenomena relate to people fulfilling roles in organizations, and the concepts used in OB pertain to entities that "exist" for a limited period of time. Thus, like commitment is bounded by the period of employment, leadership is bounded by the fulfillment of a leadership role, and organizational structure is bounded by (periods in) the life span of the organization.

In our view the study of $\mathrm{OB}$, refocused on temporary and changeable phenomena, should have a threefold aim: (1) to identify the critical characteristics of the phenomena, (2) to establish their causal relationships, and (3) to assess the stability and change of the phenomena as well as their relationships over longer periods of time. Applied to the example of commitment, the first aim would mean that research be directed towards the typical patterns of development of commitment among various types of employees (as well as major deviations from these patterns). 
The second aim implies that these patterns be related to (critical characteristics of) antecedent phenomena, such as leadership and rewards, as well as (critical characteristics of) consequent phenomena, such as productivity and turnover intent. The third aim means that research should find out whether patterns of commitment, and/or causes and effects, are stable over the years or show changes that can e.g. be connected to economic cycles, long-wave social trends, or generational succession. ${ }^{1}$

Key issues

Before examining the implications of the radical temporalist approach for the study of OB, there are a number of conceptual issues to consider. We will discuss:

1) the location of phenomena along the time-axis

2) temporal characteristics and parameters of phenomena

3) temporal relationships between multiple phenomena.

\section{Location of phenomena along the time axis}

We start from the axiom that the individual's life - in a metaphorical sense also the organization's life - extends in time from the moment of birth to the moment of death, and propose to look at people as simultaneously moving along a time axis at a common speed defined by the clock. The very moment in which human (inter)action takes place, is designated as 'present' and can be compared to a pointer that moves along the time axis, separating the 'past' from the 'future'. There are many notions that can help to relate the abstract notion of a time axis into real-life events and activities. Using conceptual tools such as calendar and clock, the time axis may be dissected into larger and smaller units, which can provide temporal referents for what people and organizations do.

A main distinction regarding the conception of the time axis is that between historical and a-historical time. Speaking about historical time implies that the time axis has a quasi-absolute 
scale and that the past is characterized in terms of an accumulating series of unique events and processes which together may affect later events. Historical time is uni-directional in the sense that everything happens only once in a continuing sequence, and extends from an infinite past to an infinite future. Ahistorical time on the other hand, stands for a conception of the time axis as having a relative scale and a limited scope. It is defined within the boundaries of an arbitrarily chosen time window only, and allows events to recur. Either way, the time axis serves to measure and compare the duration and dynamics of phenomena, but also to locate them in time. This is important for ascertaining which comes first, an obvious prerequisite for assessing causality, but also to identify dependencies on other, e.g. contextual factors.

A radical temporalist approach to $\mathrm{OB}$ as proposed here first of all poses the requirement of locating phenomena along the time axis. Whether to choose for historical or ahistorical time is something which will depend on the particular research aim. Since there is a general preference in the study of OB, as well as in other fields of social and behavioral science, for theories with universal validity, time is typically conceived in an ahistorical way. This means that time is referred to as e.g. $T_{1}$ and $T_{2}$ separated by an interval of known duration, that is, in relative terms. Although this choice brings certain advantages, to be discussed later, it has the disadvantage of leaving the influence of unique events, particular sequences, and cumulative developments unaccounted for.

If one were interested in ascertaining the effects of events such as "September 11" or the Enron Scandal, one would obviously have to mark the phenomena under study on a historic time axis. The study of differences (or similarities) between successive generations of managers or employees would also call for historic time. And the same applies to the study of the antecedents and impact of "new" information technologies on communication and decision making in organizations. This is not to say that research cannot or should not identify generalities, but 
merely that in order to create possibilities for identifying and analyzing differences and changes over time, such phenomena should be marked on the appropriate time axis. Put in other words, the use of markers on the historic time axis is a necessary requirement for generalization ${ }^{2}$. Historically anchored social research is scarce. An example is the study by Meloen on the development of authoritarianism and its relationships to economic growth and decline (Meloen, 1983).

\section{Temporal characteristics of phenomena}

The basic temporal characteristics of phenomena were mentioned when presenting the model in Figure 1. We distinguish the moment in which a phenomenon starts (onset), the moment in which it ends (offset) and, in between, a temporal interval of a certain duration in which the phenomenon is present in a particular form, referred to as its dynamics ${ }^{3}$. Clearly, one can differentiate between many different types of dynamics, as is illustrated by the examples in Figure 2. Thus, the phenomenon can have a constant intensity, one that increases or decreases linearly, one that increases or decreases in a non-linear but monotonous way, one that fluctuates between different levels, and so on. These forms can be characterized by parameters, like the minimum and maximum of the curve, its slope or derivatives at different points.

\section{Here Figure 2}

Certain phenomena in $\mathrm{OB}$ - perhaps even a great deal of them - can be called recurrent, which is to signify that after having finished, and after a particular amount time has lapsed, they occur again ${ }^{4}$. A good example is the task performance of a worker which typically starts in the morning and finishes in the late afternoon of five out of seven days a week, during a longer period of employment. Activities of managers and leaders, as well as interactions within work teams, although rarely depicted in this that way, show much the same pattern. Other, non-task related activities, largely irrelevant from the organization's point of view, take place in between. In 
contrast, organizational citizenship behaviors, such as visiting a sick colleague or organizing a social gathering, or counterproductive behavior, such as gossiping or engaging in private activities at work, may occur only rarely and irregularly, with large time intervals. Looking at the number of times a phenomenon manifests itself, the possibilities range from a single occurrence to a repeated one, either of a regular or of an irregular type. Figure 3 gives some illustrations. In panels $\mathrm{a}$ and $\mathrm{b}$ each manifestation of the phenomenon is of similar form, but the time interval varies. In panels $\mathrm{c}$ and $\mathrm{d}$ both the form and the time interval differ.

\section{Here Figure 3}

Recurrent phenomena ask for a different description than singular phenomena. Although one can speak of an initial onset, a final offset, and an overall duration, the description of the overall dynamics requires a hierarchical representation. Thus, each manifestation of the phenomenon can be considered as its first order appearance, and its repeated occurrence as a second order appearance. When there is recurrence in the second order appearance, a third order appearance can be defined, etc. Figure 4 gives an illustration based on the dynamics of workers' performance. The first order appearance shows the course of performance during the work day, the second order appearance shows performance during the days of the week Also shown is a third order appearance during three consecutive weeks. This example, which is modeled after empirical research of worker productivity (Alluisi \& Morgan, 1982) serves to illustrate that although the daily pattern of performance remains visible at all three levels, the second order phenomenon shows a weekly pattern with an increase from Monday to Tuesday and a decline until Friday. The third order phenomenon shows an increase over the weeks, e.g. as a result of learning. 
Apparently, recurrence does not apply to all behavioral phenomena. A distinction must be made between temporary phenomena, which have an off-on character that allows them to occur repeatedly during a long-term interval, and persistent phenomena that are manifest in some degree during the whole interval. Thus, task performance and the fulfillment of leadership roles, which relate to discrete action goals are typically recurrent (i.e. "off" during free time). In contrast, work related attitudes such as satisfaction and commitment can be assumed to be present "all the time" (i.e. till the end of the employment relationship), be it in varying degrees.

The reason for making all these distinctions is that they help to develop a better understanding of behaviors in organizations than the study of variables allows. It opens the way to study facets of phenomena, such as different modes of change and stability, that differentially relate to variations in the (physical, social, economic) circumstances to which people are exposed, as well as to the effects on other people (superiors, colleagues, subordinates) and the organization as a whole.

\section{Temporal relationships between phenomena}

Behavioral phenomena do not happen in isolation. They are normally preceded by certain phenomena, accompanied by others, and followed by others. We propose to make a distinction between antecedent phenomenon, focal phenomenon, and consequent phenomenon ${ }^{5}$, leaving accompanying phenomena (and a forteriori compound behavior patterns comprising multiple phenomena) out of account. The aim of theory and research in OB can be described as identifying causal relationships between phenomena. For example, the exposure to a job with a low degree of autonomy might produce a decrease job satisfaction and organizational commitment, while both could generate an intention to leave the organization. Another example is taken from a study by Witt, Kacmar, \& Andrews (2001) on the effects of procedural justice on employee commitment. Here, the behavior of the supervisor is the antecedent phenomenon, procedural justice as 
experienced by subordinates is the focal phenomenon, and employee commitment and satisfaction are the consequences. Obviously, we can describe the relevant (change in) behavior of the supervisor in terms of the moment it starts, its duration, and its form (e.g. increasing unfairness, low frequency of unfair treatment). But the same scheme can be applied to the experienced procedural fairness, that is, we can describe when the subordinate starts perceiving the unfair treatment, whether it first increases and next fades out, how long it persists, etc. The consequence, i.e. a change in commitment and/or satisfaction can also be described in this way, that is, in terms of onset, duration and dynamics. Since the general purpose of theorizing and research is to determine the links between antecedent, focal, and consequent phenomena, their temporal facets will have to be interrelated. In the next section we will present a scheme to guide theory development and research in this respect.

It should be noted that the distinction between antecedent, focal and consequent phenomena is a logical one, stemming from a particular view on temporal and causal order. However, a set of phenomena may occur in parallel and show reciprocal causality, with a smaller or larger delay. This is typical for so-called 'dynamic interaction' or 'dynamic social influence'. The exchange of ideas and feelings between the leader and the members of a team during a working day may serve as an example. It takes place in an ongoing process and develops in conjunction with the team's performance.

\section{Theory development}

The temporalist approach has far reaching implications for theory development in OB. Before discussing some possible directions of future theory development, we give an example that illustrates how our current way of developing theories may change by taking time into account. We take the much investigated phenomenon of organizational commitment and the three component model of Meyer \& Allen (1991). Several researchers have raised questions about the 
conceptual status of affective, normative and continuance commitment, and wondered whether they are three forms of commitment or rather three sources of commitment. Noting that they are somehow different in their origin and effect several authors (e.g. Cohen, 2003; Ko, Price, \& Mueller, 1997) have chosen to focus on affective commitment as the core concept. When we assume that feeling committed is a phenomenon that is bounded in time and that it has a certain dynamics, it becomes clear that there are marked differences between the three types of commitment. Affective commitment is likely to emerge around the moment of organizational entry, to show some downward and/or upward changes, and to disappear around the moment of leaving the organization. The origin lies in the psychological contract established at the beginning of employment. While negative experiences can weaken affective commitment, positive exchange experiences are likely to strengthen affective commitment. Normative commitment, however, may not be present from the start. Unlike affective commitment it is fully dependent on what happens after the moment of entry, and it may take considerable time to develop. With negative experiences it may disappear before the end of the employment period. The life cycle of continuance commitment seems to depend little on the specific exchange relationship with the organization and the duration of employment. On the contrary, it is much more likely to depend on the person's age and human capital (education, competences, etc.).

Although several researchers have engaged in longitudinal studies of commitment (Beck \& Wilson, 2000; Holton \& Russell, 1999; Kammeyer Mueller \& Wanberg, 2003; Meyer, Bobocel, \& Allen, 1991), we are not aware of any research that has explicitly focused on the difference in life cycle between these three commitment concepts. From a temporal perspective it seems most unlikely that a single phenomenon is underlying the three dimensional measures of organizational commitment. Temporal analyses might clarify this issue and explain the 
differences between the three types of commitment observed in longitudinal research (Jaros, 1997).

Adopting the notion of phenomena and looking for the various ways in which time can play a role, opens a perspective on OB that is much more differentiated than we have been used to. It is like using a prism and discovering that each attribute of behavior is turned into a spectrum of events. To avoid falling in bewilderment about the many differentiations that time offers and to organize the process of theory development, some systematic method to guide scientific inquiry is needed. In this section we will discuss four topics. First, the conceptualization of OB-phenomena - this implies the re-conceptualization of existing variable-based notions. Second, the design of theoretical models that involve multiple phenomena, and the formulation of research questions and hypotheses. Third, the extension of these models by including subjective time. Fourth, the issue of temporal continuity, or the stability and change over long time periods.

\section{Re-conceptualization}

Since the theory of OB has been developed with variables as building blocks and the current knowledge base is organized in terms of variables and relationships between variables, some conceptual work is needed to prepare for the study of phenomena. How do we build on existing knowledge when substituting variables by phenomena and introducing time? Our suggestion is to assume that well-examined variables may be related to phenomena, and to begin delineating and specifying those phenomena. Just as for leadership, which was mentioned as an example above, this might work for decision-making, communication, commitment, satisfaction, group potency, group diversity, and other variables as well. Perhaps not all variables will have a corresponding phenomenon - e.g. there may be more than one variable that refer to the same phenomena (e.g. multiple leadership styles may relate to one phenomenon: leadership) - but one will obtain at least 
a list of ideas about phenomena to study. In addition, it may also be valuable to use fresh observations from field studies since new phenomena may emerge over the years and some phenomena may have been overlooked by researchers working within a timeless frame of reference. But for the time being we would suggest to focus on phenomena that are close to what has already been studied by researchers in the OB community.

A number of points are to be taken into consideration when specifying phenomena. First, it is advisable to use verbs (lead, communicate) or verbal nouns (leading, communicating) to refer to phenomena in contrast to the practice of using nouns (leadership, communication) to refer to variables. The reason is that the verbal form promotes to think of actions, processes, and changing states, and prevents thinking in terms of stable attributes. Second, one should specify the subject(s) and/or object(s) involved in the activity or process. In OB, the subject (sometimes referred to as 'actor') is typically a person, a dyad, a group, a cohort of people etc. Objects may be other people, affected by the actor(s), but also the environment or parts of it, such as tasks or roles, the system of reward, a work technology, or organizational structure. Temporal parameters may be different for each type of subject or object. For example, the development of an individual's commitment over time, may differ from that of a cohort of people. In this context, one should also specify the level(s) at which phenomena manifest themselves. Temporal parameters are likely to be quite different at lower and higher levels. For instance, at higher levels changes may be delayed or slower compared to lower levels. Third, one should articulate the nature of the phenomena involved, that is specify whether they consist of actions by people (such as leading, performing), mental processes (such as intending, thinking), social processes (such as communicating, exchanging), physical processes (such as confining, charging) or altering states (such as fatigue, stress). Fourth, one should identify temporal characteristics, e.g. frequency, duration, variability, timeliness, increase, or speed that are of particular relevance for the 
phenomenon. In connection with motivation one might think of stability and duration, in connection with planning behavior of timeliness, and in connection with organizational learning of growth and variability. Questions as to "how often, "how long"”, "how late" etc. may be helpful in making these aspects salient.

At some future point in time, when enough progress in reconceptualization has been made, it may be possible to classify phenomena according to temporal features. Thus, one might differentiate between slow and rapid (catastrophic) organizational phenomena, or between recursive processes at the individual or group level, etc.

\section{Theoretical models and research questions}

To get an idea of the effect that the study of phenomena will have on the theoretical models of $\mathrm{OB}$, we suggest to consider another example. In Figure 5 we compare a three-variable model, comprising an antecedent variable $\mathrm{X}$, a focal variable $\mathrm{Y}$, and a consequent variable $\mathrm{Z}$. The arrows between the variables are supposed to represent causal links, meaning "X leads to Y", "Y leads to Z". This is a standard model in which numerous OB-variables can be meaningfully substituted for $\mathrm{X}, \mathrm{Y}$ and Z. It should be noted that the expression "leads to", although commonly used by researchers, is multi-interpretable. The most common interpretation is that of a statistical association, whereby an increase in $\mathrm{X}$ leads to an increase in $\mathrm{Y}$, etc. For comparison we give a model comprising three phenomena, also labeled $\mathrm{X}, \mathrm{Y}$ and $\mathrm{Z}$, with corresponding causal relationships. In the second model the arrows cannot carry the general meaning of "leads to" as several different effects are possible. For example, the arrow from $\mathrm{X}$ to $\mathrm{Y}$ might be read as "after a certain exposure to a particular pattern of $\mathrm{X}$, and after a given delay, there will be a change in $\mathrm{Y}$ ", and the arrow from $\mathrm{Y}$ to $\mathrm{Z}$ might be read as "if $\mathrm{Y}$ has changed durably, there will after some time be a certain type of change in Z". Thus, using building models from phenomena rather than 
variables call for a much greater degree of specification about what is supposed to happen in reality.

The relevance of these distinctions might be illustrated by reference to models that have been proposed for the study of stress. Thus, Frese and Zapf (1988), when discussing possibilities for studying the impact of a stressor on people's ill-health, distinguishes between an exposuretime model, in which the incidence of ill-health increases with the duration of the exposure to the stressor, and an initial impact model, in which ill-health is an immediate response to the shock of being exposed to the stressor, and has the tendency to reduce over time. Frese \& Zapf (1988) state that these two models do not sufficiently account for the actual dynamics of stress. They propose five variants to the exposure time model ${ }^{6}$ which differ in latency time and the shape of the growth curve, and propose to combine the exposure time model to the initial impact model. These and other possible models are subsumed in the general scheme for analyzing temporal relationships introduced here above.

\section{Here Figure 5}

\section{An analytical scheme}

As is clear from the example, building models that specify the relationships between three (or more) phenomena is not an easy task, since there are many temporal parameters to be considered. In order to guide the process of identifying and specifying interesting relationships we propose a conceptual scheme (see Table 1) that makes use of the basic temporal characteristics of phenomena that were introduced above. Using this scheme will help to organize the process of developing theoretical models and formulating research questions. The scheme applies to the temporal facets of any pair of the antecedent, focal and consequent phenomena.

\section{Here Table 1}




\section{Prototypical research questions}

The scheme allows us to generate nine prototypes of research questions (or hypotheses) for any pair of phenomena. We will briefly discuss these questions with regard to the combination of antecedent and focal phenomena. When discussing types of temporal research in section 5 , we will give examples of specific research questions formulated after these five prototypes.

1. How much time lapses between the moment of onset of the antecedent and the focal phenomenon? The amount of delay can be designated as 'latency time', 'effect period' (Cohen, 1991) or 'incubation time'. In behavioral terms it could be indicative of a process that leads to the build-up of a behavioral response. It will often include interpretation, comparison to others, social validation, sense-making etc. In some cases the delays could be large, something which is known as "sleeper effect"(Frese \& Zapf, 1988). With other behaviors, response times can be very short and antecedent and focal phenomena can overlap. Example: if experiences at work are supposed to influence experiences at home, either by of spillover of compensation (Heller, Judge, \& Watson, 2002; Jones \& Fletcher, 1996), it would be important to know whether such effects occur after a substantial lapse of time or immediately.

2. How does the onset of the antecedent relate to the duration of the focal phenomenon? The location of the onset on the time axis (e.g. early or late with respect to a standard, or in comparison with others) might affect the content of the interpretation and influence the persistence of the response. Example: being the first to experience unequal treatment may produce a stronger and more persistent feeling of injustice than being the last.

3. How does the onset of the antecedent relate to the dynamic form of the focal phenomenon? Similarly, the timing (location on the time axis) might affect the form of the response. Example: see above. 
4. How does the duration of the antecedent relate to the onset of the focal phenomenon? A long duration might enhance the motivational force that leads to the build-up of the behavioral response, and hence reduce the 'latency time'. Example: longer sexual harassment will produce a faster response in the victim.

5. How does the duration of the antecedent relate to the duration of the focal phenomenon? A long duration might enhance motivation and similarly lengthen the duration of the behavioral response. Example: longer exposure to planned organizational change may lead to more persistent employee resistance.

6. How does the duration of the antecedent relate to the form of the focal phenomenon? A long duration might also affect the way in which the response develops. Different possibilities would be a slowly raising curve due to "habituation", or a steeper curve due to enhanced anticipation of effects. A long existing leader-follower relationship or psychological contract may produce high and stable levels of satisfaction and trust.

7. How does the form of the antecedent phenomenon relate to the onset of the focal phenomenon? The fluctuating exposure to an environmental condition will have more effect than exposure to a constant or slowly rising condition. For example: the way in which customers confront an employee with challenges or obstacles may lead to greater frustration and a faster onset of the response.

8. How does the form of the antecedent relate to the duration of the focal phenomenon? The pattern of exposure may well influence the response. For example: increases, decreases or alternating levels of rewards given by the boss may produce very different effects on the duration of the behavioral response. Or: certain ways of coping with occupational strains may have only short-lived effects. 
9. How does the form of the antecedent phenomenon relate to the form of the focal phenomenon? The pattern might be reciprocated, as strong responses might cyclically alternate with strong pressures. For example: a decreasing appeal from colleagues might lead to a low and constant level of response. Or: spill-over from work to family life might build up slowly or rather fast.

The scheme can also be applied to the relationship between focal and consequent phenomena, producing similar lists of prototypical questions ${ }^{7}$. Thus, instead of cases in which environmental factors, especially activities of superiors, colleagues, and customers impinge on the individual employee and evoke certain behavioral or attitudinal responses, we can address cases in which employee behaviors affect all sort of organizational processes, such as e.g. innovation, organizational change, and organizational effectiveness.

The examples given should remind us of the fact that $\mathrm{OB}$ theories involve entities at different levels, and which are likely to differ with respect to their temporal parameters. E.g. when studying the effects which changes in management team composition (antecedent) have on within-team processes (focal) and subsequently on firm performance (consequent), it should be kept in mind that each of these phenomena its own dynamics, that there are likely to be delays in the onset of effects, and that different time scales are needed to gauge relevant events. The same is true for the effects of downsizing at the company level (antecedent) on employee trust (focal) and subsequent employee loyalty or performance (consequent).

\section{Mediation effects}

There is no treason limit the application of this scheme to adjacent pairs of phenomena (i.e. antecedent-focal or focal-consequent). On the contrary, it is also interesting to consider the temporal relationships between antecedent and consequent phenomena, and to compare those with the temporal relationships between the focal and consequent phenomena. A look into the links 
between the onset, duration and form of all three phenomena may shed a new light on 'mediation' effects. Obviously, in the framework of a temporal analysis it is not sufficient to follow the standard practice of demonstrating an improved prediction as a result of including a mediator variable between a dependent and an independent variable (Baron \& Kenny, 1986). One would only speak of mediation when specific hypotheses on the effect of the focal phenomenon on the onset, duration and form of the consequent phenomenon were proven to be correct, and when these would provide a better overall explanation than competing hypotheses based on the antecedent phenomenon. A key issue would be the time which passes till the onset of the consequent phenomenon. A mediating effect in sensu strictu can only exist when the onset of the consequent phenomenon occurs after the onset of the focal variable. Thus, retaliation as an organizational response to reports of sexual harassment (Bergman, Langhout, Palmieri, Cortina, \& Fitzgerald, 2002) cannot be called a mediator in the relationship between reporting and psychological outcomes, unless the onset of retaliation takes place before the onset of the particular psychological outcome. Similarly, trust cannot be called a mediator of the relationship between interactional justice and job satisfaction (Aryee, Budhwar, \& Chen, 2002), unless the onset of changes in trust precedes the onset of changes in satisfaction. Examples like these suggest that with the radical temporalist approach mediation effects are much less likely to be found than in the traditional approach. Including these and other temporal effects will make our knowledge of the phenomena much more profound, however.

\section{Limitations}

It should be acknowledged that the three-phenomenon model and scheme for analyzing the relationship between pairs of phenomena have their limitations, and should not be expected to fully grasp the complexities of the organizational reality. We should keep in mind that phenomena may manifest themselves in waves or patterns and that they affect other phenomena 
simultaneously. For instance, changes in markets and technologies, coinciding with mergers or acquisitions, may produce simultaneous changes in organizational structure, management styles, reward policies, and these may have simultaneous impacts on employee satisfaction, commitment, turnover intent, etc. Even though it makes sense to start with analyzing the relationship between single adjacent phenomena, the theory of $\mathrm{OB}$ should also account for cause-effect chains that involve multiple phenomena and/or manifest themselves on along term. We will come back to the issues when discussing future challenges in section 7 .

\section{Substantive theorizing}

The scheme for analyzing temporal relationships and the prototypical questions resulting from it may indicate a way to structure the development of OB-theory, but it says little about substantive content. From a pragmatic point of view, the best approach to the development of time-based theory is probably to start from two sides. On the one hand one may depart from existing and well-supported models found in the OB literature, especially those which actually have already been investigated longitudinally, and expand them by incorporating lacking temporal aspects. On the other hand, one may adopt a Greenfield approach and launch new studies that generate proper time series data right from the start.

Building on existing theory means generating ideas about temporal features that may improve or clarify current explanations. For example, in the study of job characteristics and their influence on organizational commitment (e.g. Flynn \& Tannenbaum, 1993; Roe, Zinovieva, Dienes, \& Ten Horn, 2000), one might hypothesize that a longer (or accumulated, or more frequent) exposure of employees to autonomy will produce a lasting increase commitment during the remaining period of employment by the organization. In the study of top management team diversity and its impact on team processes and firm outcomes (Hambrick, Cho, \& Chen, 1996), one might, analogously, hypothesize that changes in teams' composition that enhance (or reduce) 
diversity will result in a higher (or lower) frequency and duration of conflicts within the team during a subsequent period. In addition, one might hypothesize that a certain rate, duration and accumulated presence of conflict, will with a certain delay produce declining business results. Which are the most promising areas to start developing truly time-based theory? If we discard longitudinal research that does not provide information on measured time and focus on those studies that have included one or more temporal aspects, we obtain a list of topics in which substantive theorizing might start. Among them are time awareness, time perception, and selfregulation with regard to time. Below we will expand on one the latter area, which deals with subjective time.

\section{Including subjective time}

In this article we focus on objective, clock-based time as an attribute of all organizational and behavioral phenomena under study. Thus, we follow an 'outsider perspective' in which selected aspects of temporality, identified by the researcher, are used to describe and explain how certain phenomena in organizations emergence and develop, and how they influence each other. The most logical way to enrich the temporal models emerging from this perspective and to build substantive theory is to also incorporate subjective time. Acknowledging that organizational actors are generally aware of time (e.g. have a view of the past and the future, note their own work tempo, perceive deadlines, plan their activities, etc.), we may well direct research attention to phenomena that do have subjective time attributes. Various researchers have adopted an 'insider perspective' on time that centers around the way in which people conceive and perceive time. Some have emphasized that time is socially constructed and that conceptions of time are culturally different (Bluedorn, 2002; Pettigrew, 1990), both at the level of national culture and that of organizational culture. For example, cultures differ with regard to the time orientation, that is the orientation on the past, present, and (near or remote) future (e.g. Hofstede, 2001; Schein, 
1985). OB researchers have investigated several phenomena of subjective time from an individual differences perspective. Among them are time orientation (e.g. Francis-Smythe \& Robertson, 1999; Zimbardo \& Boyd, 1999), polychronicity (e.g. Palmer \& Schoorman, 1999; Slocombe, 1999), time pressure and time urgency (Rastegary \& Landy, 1993; Waller, Conte, Gibson, \& Carpenter, 2001), and pacing styles (Claessens, 2004; Gevers, Rutte, \& Van Eerde, 2004) .

Although, subjective time is of interest for its own sake, particularly challenging research questions emerge when objective and subjective time are looked upon simultaneously. The reason is that people's subjective perceptions of time or temporal facets of their own or other people's behavior may affect the objective properties of their subsequent behavior. For example, workers who perceive a lack of progress in their work compared to some objective deadline (e.g. calendar date) may speed up their behavior. Similarly, those working faster than their colleagues may slow down. Regardless whether this is explained in terms of self-regulation or adjustment to others (entrainment, McGrath \& Kelly, 1986), it points at the interdependence and interaction of objective and subjective temporal features of certain phenomena. Inspiration for theory-building and research may be derived from areas in which objective and subjective time have already been studied in some depth. An example is the area of shift work, in which objective features of shift schedules have been investigated in relationship to workers' perceptions of time and subjective states, such as fatigue (Luna, French, \& Mitcha, 1997; Totterdell, Spelten, Smith, Barton, \& et al., 1995). Another area is that of work planning and performance. Here, a number of studies have demonstrated how objective deadlines affect both planning behavior and selfregulation over time, both among individuals (Claessens, 2004; Kaufman-Scarborough \& Lindquist, 1999; Macan, 1994) and groups (Gevers, 2004; Seers \& Woodruff, 1997; Waller et al., 2001; Waller, Zellmer Bruhn, \& Giambatista, 2002). A third area is that of entrainment in 
groups, where group members adopt the same temporal, e.g. cyclical, pattern (Ancona \& Chong, 1999; McGrath \& Kelly, 1986).

Of course, it should be kept in mind that objective time and subjective time are distinct concepts (Grondin, 2001), and that not all objective temporal facets of behavior are reflected subjectively. It is well known that people may perceive the flow of time very differently from the passage of objective time (Bluedorn, 2002). Moreover, people in organizations may not be aware of the delay in their response to a pay rise, fluctuations in their level of involvement, the duration of exposure to a change program, the superior's change of leadership style, etc.

By incorporating subjective time, one can formulate a broad range of research topics, related to

- perception of time markers and time flow, e.g. during the hours of the day, the days of the week etc.

- perception of time standards, such as standards pertaining to duration, speed, progress, deadlines etc.

- time-related states, such as haste and boredom.

- self-regulation regarding to the temporal aspects of own behavior

- social interaction and group level-regulation of activities.

Each of these topics represents a potentially interesting area for research. This may be illustrated for the topic of standards. Since temporal standards play an important role in organizational life, the study of how people perceive and respond to whether events are late or early (compared to a deadline), long or short (compared to a standard of duration), slow or fast (compared to a standard of rate of growth or frequency of repetition), little or much (compared to a standard of degree growth or amplitude) may give insights in feelings and actions that are hitherto unknown. Take for example the case of responses to fair and unfair treatment. Whether 
an employee sees a given treatment as fair or unfair, may depend on whether he perceives it as being received late, earlier or later than others, longer or shorter etc. Similar examples can be given for the other topics listed. As for social interaction, it becomes relevant whether members share the same views on the importance of time, whether they act fast or slow, whether they follows orders and requests immediately or with delay, etc.

\section{Looking at history}

The third type of research puts temporal phenomena in a broader context. It becomes relevant after the dynamics of a particular temporal phenomenon or a cause-effect relationships has been established. Its focus is on the generalizability of the findings over a large time span. Thus, if the dynamics of job satisfaction has been shown to have a certain typical course over the job's life span, a study might be conducted to find out whether this form remains the same in subsequent time periods, or whether its parameters change over time. Similarly, if it has been found that subordinates respond with increasing compliance to a leader who consistently exhibits a certain leadership style in a six week time frame, it remains to be seen whether that response keeps showing up in subsequent studies, performed across the years. The issue here is that the conditions under which the separate studies were done, and that were not captured within the limited timeframe of those studies, may change and affect some features or the very nature of the phenomenon.

Three different possibilities come to mind, when addressing this issue. First, the possibility that novelty has an influence on people's attitudes and behaviors. One might think of the 'Hawthorne effect' as a case in point, but also of studies on the introduction of new work arrangements, such as productivity measurement and enhancement (Pritchard, Jones, Roth, Stuebing, \& et al., 1988) or self-managing teams (Manz \& Sims, 1993) in which the initial enhancements of attitudes and performance behaviors have appeared difficult to replicate. The 
second possibility is that of conditions changing in a cyclical way, such as the seasons, alternating phases of company growth and decline, and cycles of expansion and contraction in sectoral or national economies. Since OB studies phenomena within organizations, the possibility that findings depend on the phase in a wider economic cycle is far from unrealistic. For example, the degree to which absenteeism and turnover intent can be predicted from job variables, may be less strong during economic recessions, when unemployment is high (cf. Trevor, 2001). The third possibility is that of changes in the society in which organizations and people are embedded. Slow trends, reflecting processes of democratization, economic development, technological innovation, and institutional transformation, may change peoples' expectations, values, and behaviors. This implies irreversible changes along the historic time axis, with sometimes unique sequences or path dependencies (Denison, 2001)

Although certain patterns in OB may be universal and insensitive to contextual conditions, it is not at all unlikely that behavioral phenomena change in the course of decades. On the contrary, when looking at organizational behaviors from a broader perspective on society and history, one would rather expect certain changes over time (Pettigrew, 1990). The acceptance and effectiveness of different forms of leadership constitute a good example. While authoritarian leader behavior has lost much of its popularity and impact since the 1940's, the opposite applies to transformational leader behavior. Changes in labor relations and prevailing conditions at the work place may have eroded the validity of the Herzberg model of work motivation. Some of the findings on technological innovation may have become obsolete due to the dramatic advance in information technology over the last decades. This to say that research should be broadened in scope as to ascertain whether or not temporal OB models retain their validity over time.

This type of historical research requires another expansion of the time scale, since it calls for replication at distant moments along the time axis. How long the scale should be stretched will 
depend on the purpose of the research. Studies on the impact of novelty may limit themselves to 10 years, while studies on the influence of economic cycles may confine themselves to a range of 5 to 15 years. Studies on historic trends will have to adopt a time frame of several decades.

\section{Research strategy}

It should be clear from the foregoing that the radical temporalist approach to the study of OB calls for a different research strategy. Building on the distinctions that have been made earlier, we propose three phases in the process of developing and testing theories about OB-phenomena, i.e.:

1. Temporal modeling of phenomena

2. Investigating temporal relationships

3. Assessing constancy of over longer periods of time.

In this section we will address exemplary research questions and main choices relating to the research design. Methodological issues related to each research phase will be discussed in the next section.

\section{Temporal modeling of $O B$ phenomena}

The first phase of the research process aims at describing, modeling and understanding temporal phenomena in $\mathrm{OB}$. This means that the focus is on the manifestation of every phenomenon among one or more individuals, groups or organizations. Examples of questions to be answered by this type of research are:

- how fast does fatigue build-up during the day?

- how does team performance fluctuate during a workweek?

- how stable is overall job satisfaction?

- how long does it take for a team to develop trust and how quickly can it disappear?

- how often and how long do employees engage in OCBs?

- how fast and how well do managers acquire a transformational leadership style? 
The first step is descriptive modeling. For this, the researcher will have to start with gathering data on the temporal facets of the phenomenon, using observations, self-descriptions, interviews, and, of course, calendars and clocks to measure time. Methods should preferably be varied and broad, that is, cover both objective and subjective, quantitative and qualitative aspects of behavior. This is particularly important when little is yet known from earlier research, since one will need clues about the onset and development of the phenomenon and one has to decide about facets to consider in subsequent research. Next, formal descriptions have to be made, showing the duration and dynamic features of the phenomenon, preferably by choosing a dynamic function that describes the phenomenon well.

The second step, then, is an exploration of the factors that might control the parameters of the dynamic function. This means looking for possible antecedents and concomitants, and generating hypotheses which hypotheses can be tested in subsequent explanatory research. For example, in studying transformational leadership one would examine people who fulfill leadership roles at several moments and during certain period of time, and look for manifestations of "transformatory" behavior. If it would appear that during a longer time interval, the transformational leadership behavior fluctuates, one would try to fit a sinusoid function and determine the parameters (i.e. amplitude and wavelength) of this function and look for factors associated with these parameters. However, if transformational leadership would develop according to a learning curve, one would want to know which factors control the speed of learning and the asymptotic level ultimately reached.

An important issue to consider is the existence of differences between individuals over time. Patterns observed for the whole sample may not be valid for all subjects. That is, there may be diverging intra-individual change patterns as well as changes in inter-individual diversity. The same may be true for differences within and between groups, and within and between 
organizations. An example is given by Hofmann, Jacons, and Baratta (1993) who demonstrate how changes in individual performance over time differ from changes at the level of the sample as a whole. A good description of the conceptual and methodological complexities of the matter is given by Bolger, Davis and Rafaeli (2003). Roe (2004) has highlighted the differences between different ways of analyzing temporal data intra- and interindividually in an analysis of simulated data.

There is a wide range of mathematical and statistical methods for analyzing temporal data, which will be discussed later (see Table 2). These methods represent different ways of identifying patterns in a three-dimensional matrix with successive observations (time series) of a number of indicators among a number of subjects or other entities. Modeling the dynamics of a particular phenomenon should be guided by the same criteria as apply to mathematical modeling in general. Thus, the model should:

- have a good fit, i.e. leave small residuals

- be parsimonious, i.e. have a small number of parameters

- have parameters which can be meaningfully interpreted

- be robust under replication in other data $\operatorname{sets}^{8}$.

Usually these criteria cannot be met at the same time, and some payoff relationship exists between them. The research should then aim for a description that gives an optimal result. We will discuss some of the modeling methods later on.

Temporal modeling is a complex matter for which no simple routines exist. The complexity derives basically from the difficulty of optimizing the solution with respect to the four criteria, but it is enhanced by a number of factors. First, the dynamics may not be the same for all elements in the sample, which calls for simultaneous analysis of within and between variability, and of multiple levels. Second, the number of parameters may become very large, especially 
when multiple indicators are taken into account. Third, observed phenomena may reflect compound forms of dynamics, deriving from different processes, which are difficult to match with a single curve. Thus, the analysis will have to disentangle short-term and long-term effects, lower and higher order effects, and to identify functions that, when superimposed, can adequately describe the total dynamic pattern.

Of course, statistical and mathematical models require an interpretation at a theoretical level. For example, a linear growth model will be interpreted in terms of an initial level and a rate of growth, and a developmental model will be interpreted in terms of stages people or organizations pass through. A distinction can be made between two major types of theories, i.e. (1) those postulating a particular dynamic pattern that has specific markers on the time axis, such as a growth or learning curve, (2) those postulating a sequence of processes or stages, which do not require specific time markers. Maslow's (1954) well-known motivation theory can be considered as an example of a stage theory. The latter type of theory does not require time to be measured at an interval scale, but accepts ordinal measurements. Theories can differ markedly in their assumptions, as is expressed in distinction between strong and weak developmental theories made by Nesselroade \& Baltes (1979). Strong theories imply universal applicability, fixed sequentiality, irreversibility, qualitativeness, structuralism and orientation towards an end-state (Nesselroade \& baltes, 1979; p.14). Weak theories do not make such assumptions but just require reliably identified changes. Comparing Aldefer's well-known theory of motivation (Aldefer, 1972) to Maslow's theory makes clear that Aldefer's theory is a weaker one.

\section{Investigating temporal relationships}

The second type of research to be discussed aims to establish cause-effect relationships and concomitant relationships between two or more phenomena. In this type of research one would generally want to know whether the occurrence of one dynamic phenomenon would produce a 
new phenomenon, whether a certain type of change would result in another type of change, and so on. Since there are multiple temporal facets of OB phenomena, several questions can be raised that are either of theoretical or practical importance. Some examples are:

- what are the causes of emerging distrust?

- what are the causes of persisting creativity?

- what are the causes of increasing work commitment?

- what are the causes of decreasing team performance?

- what are the causes of variability in OCB?

The "what" in all these questions relates to things that happen in time, that is other phenomena which occur either in the environment or in the person or group, or a particular temporal aspect of it. The questions point at the potential interest of the causes of a phenomenon's onset, duration, increase, decrease and variability. When dealing with a recurrent phenomenon (see above) the list of questions can be expanded by addressing the causes of changes in the pattern of repetition. These changes could pertain to intervals between recurrences, their number (or frequency), or the amplitude. For instance:

- what are the causes of an increase in rate of within-team conflict?

- what are the causes of a decreasing numbers of error rates?

- what are the causes of increasing variability of OCB?

As was true for the type of research discussed above, there is a need for descriptive and exploratory research in the first place. Using a variety of quantitative and qualitative methods researchers should gather information on the links between onset, duration and dynamics of multiple phenomena. Since there is not much pertinent knowledge to rely on in the current OB literature, preceding research on the dynamics of separate OB phenomena will be of great help in focusing research studies on the right type of issues, and drawing up hypothetical models of 
causal relationships. E.g. knowing how organizational commitment of employees emerges and declines, and what form the development may take, one can search for links with preceding events in the interaction between employees and managers, and formulate specific hypotheses. One type of hypothesis, derived from the literature on the psychological contract (Robinson \& Morrison, 2000; Rousseau \& Wade Benzoni, 1995), might read that singular events, such as an unexpected treatment by the manager, will lead to an sudden drop of commitment. Another hypothesis might be that long term exposure to the same job will produce a slow decline of commitment. Such specific hypotheses will constitute the input for explanatory research studies, which should in the long run produce knowledge about the relationships of temporal phenomena.

The logic of this type of research can be applied in various ways. Instead of looking at the causes of particular OB-phenomena, the research focus can also be put on the effects. Research questions about effects, again to be understood as temporal phenomena such as performing in a different way or behaving differently in the work team, make a lot of sense from a theoretical as well as a practical point of view. This point is well illustrated by the following questions ${ }^{9}$ :

- what are the effects of emerging distrust?

- what are the effects of persisting creativity?

- what are the effects of increasing work commitment?

- what are the effects of decreasing team performance?

- what are the effects of variability in OCB?

And similarly:

- what are the effects of an increase in rate of within-team conflict?

- what are the effects of a decreasing numbers of error rates?

- what are the effects of increasing variability of OCB? 
Of course, this list may be expanded with questions about the effects of individual, team based, or organizational interventions, such as the introduction of another reward system or the implementation of an organizational change program.

Research into the temporal relationships between two or more phenomena is of a different nature than research into a single phenomenon. It will generally focus on selected parameters of the distinct phenomena and establish their interrelationships. For instance, one will look at the frequency of intra-role conflicts and relate it to the upward slope of the curve describing the augment of strain. In terms of the basic methodology this type of research is similar to traditional research in $\mathrm{OB}$, which concentrates on variables. However, since the parameters relate temporal facets of which there may be many, the research is clearly more complex. The 3-dimensional data matrix, referred to above, comprises both a larger number of variables and a larger number of observation moments.

Again the researcher has to address differences between individuals, or between groups or organizations, and various types of nesting (multiple levels) which may be present in the data. For instance, subjects will be nested in teams and perhaps teams in larger organizational units. In some situations it may be difficult to make overall evaluations of the relationships between multiple phenomena. It necessitates one to proceed in a stepwise manner and carefully construct an overall image by studying several specific links one by one. This can be done by using the logic demonstrated in Table 1.

\section{Assessing constancy and variety over longer periods of time}

The third type of research focuses on generalizability. It examines the results of research described in the preceding sections (on temporal models and temporal relationships) and compares findings from different time periods. The aim is to establish whether the findings remain stable or reflect change. Time periods may differ in length; they would typically range 
from seasons or quarters to years, decades or even longer periods, such as historical époques. Depending on whether the researcher looks at time in an ahistorical or historical way, a wide range of research questions may be investigated; for instance:

within an ahistoric view of time:

- to what degree do learning curves change when employees grow older (life span)?

- does weekly performance show the same pattern within the quarters of the year?

- are there variations in the duration of intragroup conflict over the seasons?

- does the variation of reflexivity in project groups remain stable as organizations gain more experience with project work?

- does the degree of innovation in organizations change over the years?

- is culture change an accelerating process over the years?

- do employees' responses to perceived organizational support remain stable over career stages?

- does the motivating effect of rewards change when employees are with the same organization for a longer time?

- does the interaction between leaders and subordinates change when leaders grow older?

- does the relationship between ability and performance decline over the years?

within a historic perspective on time:

- are there difference in motivation, performance, leader behaviors, group interactions, organizational performance etc between generations?

- is the dynamics of behaviors and interactions different before and after important events, such as the end of the Cold War, "9-11", the $2^{\text {nd }}$ Gulf war etc.?

- are there changes over the years and decades, e.g. when technology and education change? 
The research on these kinds of questions may be pursued along three different lines. The first one is motivated by a search for generalizability only and is guided by the hypothesis that certain dynamic aspects of phenomena or the relationship between two phenomena, will remain stable. For example, several studies in the field of personnel selection have looked into the stability of ability-performance relationships. Rather than finding the hoped for stability a gradual decline in validities over time was found (e.g. Henry \& Hulin, 1987). The second line takes a broader look and aims to understand the factors that control stability and change. While the first approach will generally be hypothesis driven, the second may be data-driven and call for descriptive and exploratory research to generate hypotheses about what is behind the changes. For example, it would examine attitudinal differences between employees of different generations or differences in behaviors observed before and after "9-11", and suggest possible explanations which could subsequently be tested. The third line could be called interpretative. It starts from an analysis of the historical and social context and tries to put findings from subsequent in a perspective.

It is important to note that stability and change of OB-phenomena are not the only foci of interest. Since people in organizations do not all behave in the same way, there is also the issue of variety. Thus, while theories will always tend to formulate general principles that apply to any individual, group or organization, observed differences between them must also be explained. This aspect gains importance in temporal research, as one should make a "distinction between changes in individual differences and individual differences in change" (Wohlwill, 1973). In other words, there may be differences in stability and change between individuals, groups and organizations, which cannot be attributed to chance and call for an explanation. For instance, employees may systematically differ in the stability of their performance, or in the speed of learning new routines. And similarly, there may be a change in the degree of variation at each of 
these three levels. Thus, the variety between individuals, or groups, or organizations, may increase or decrease over time. E.g. socialization is likely to lead to increasing homogeneity in individual norms and values. Prolonged interaction between teams may lead to increasing intergroup differentiation. Although these issues are also relevant in temporal modeling and research on temporal relationships between phenomena, they are particularly important when looking at stability over longer time spells.

\section{Research methods}

Adopting the radical temporalist approach necessitates the researcher to design research studies in a different way and to use different methods of analysis from those typically used in OB research. In this section we will first address some basic issues relate to the choice of the proper time scale, time sampling, time measurement etc. Although they are sparsely covered in the research literature (see e.g. Menard, 1991), considering them is important because they are critical for making adequate research designs. Secondly, we will mention some specific problems (relating to sequence, delay and control) that emerge when studying temporal relations. Thirdly, we will review a number of methods of analysis that can be used when investigating the three types of research questions outlined above.

General methodological issues

\section{Time scale}

A major issue for the researcher to decide about is the time scale. First, it has to be decided whether time is supposed to be absolute or relative, and to be unidirectional or recursive. When phenomena occur repeatedly, as is the case with behaviors related to diurnal cycles or daily work routine, a relative time scale ${ }^{10}$ is required. This allows one to determine the moment (within a day or week) in which the phenomenon starts, as well as its duration. In this case it does not matter on which dates the measurements take place, nor whether this happens at T1 - T2 - T3 or at T2 - T3 - 
$\mathrm{T} 4{ }^{11}$. When phenomena are unique and happen in a specific sequence, one would need an absolute time scale that allows one to identify the calendar date, and perhaps the hour of the day. This makes sense when phenomena relate to dramatic events in the life of an individual, group or organization, or to specific paths of development. Examples would be the launch of a new product, the merger of two companies, a large-scale strike, a downsizing operation, a change of political regime, the break-out of a war. This type of time scale is also useful in temporal conditioning research, for instance the aim is to find out whether recurrent phenomena do change over time. In the previous section it was pointed out that questions of stability and change do not always call for historic time, but may also involve non-historic time. If this is the case, a quasiabsolute time scale suffices; that is, a scale that uses all categories of the calendar except for the precise year.

Secondly, the resolution of the time scale has to be determined. Here, a wide array of options is available, ranging from seconds on the one hand to centuries on the other hand. Obviously, the resolution should neither be too fine nor too coarse, and should depend on the nature of the phenomena to be studied. Thus, the smallest time unit to detect changes in job satisfaction is probably a day or a week, and certainly not an hour or a minute. But the study of fatigue in relation to rest breaks may well require a smaller time, such as hours or minutes. Changes in team composition and performance, or organizational change processes require time scales with much larger units, such as week, months, or quarters. Special attention is required when two or more phenomena differ in their dynamics, e.g. when short-term events such as mobbing or unfair treatment by the leader are linked to employee attitudes and group performance. In this case the resolution will have to depend on the smallest time-unit involved. Table 3 shows how relative and (quasi)absolute time scales come together and help to choose the proper degree of resolution for the phenomena under study. In OB the relative time 
scale is typically defined by the phenomenon under study (e.g. weekly work performance), while the absolute scale is needed for conditioning research.

\section{Here Table 3}

\section{Time frame and grid}

Once the time scale has been chosen, the researcher should set the total time frame for the study, that is to decide when the first observations will start and the last observations will end. This issue is of obvious importance in planning longitudinal research studies, as a certain amount of time is needed to allow for the dynamics of each phenomenon and for the processes by which one phenomenon influences the other, including the 'effect period'. Setting the timeframe marks an important difference between traditional "timeless" studies of OB-phenomena and studies in which the same phenomena are studied from a temporal perspective. Thus, in a traditional study of autonomy, job satisfaction, commitment and intention to leave the time frame would normally be limited to a few weeks. Its length would derive from the time it takes to collect the data from a sufficient number of respondents, not from suppositions about the dynamics of the phenomena. Ideally, in this type of research, one would prefer a time frame of a single day, and avoid a longer time frame that would produce variation in the moment of measurement. In a temporal research study the time frame would be long enough to cover a minimal employee exposure to (or a minimal amount of change in) autonomy, a change in satisfaction and/or commitment, and a change in the intention to leave, and it would include the time needed for intermediary processes (communicating with others, interpreting) to take place. Thus, instead of a single day it might cover several weeks. Ettlie (1977) has pointed at methodological and practical aspects of choosing the time frame. Generally speaking, a longer time interval makes the study more vulnerable to the influence of other factors, which may not be fully known or controlled, and requires more data 
collection efforts. However, the interval should be long enough as to include a base-line assessment and to familiarize the respondents with the data collection procedures.

The next issue to decide about is how many moments of observation there should be and how they should be spaced over the time frame. This issue has received considerable attention in the research literature on psychological development and learning (e.g. Cohen, 1991). A problem pointed at is that research designs with few moments of measurement and large intervals pose the risk that changes in between those moments of observations remain unnoted. Thus, for instance, if there would be an increase in performance followed by a decrease in performance in the interval T1-T2, one would wrongly conclude that there has been no change from T1 to T2. After all, the only form of change between two points in time can be a straight line (cf. Rogosa, 1995). Increasing the number of observation moments, adopting a finer time grid, would give a better view of changes. The shadow side of this is that more observations require more resources (such as money, and involvement of subjects). When resources are limited the researcher may have to reduce the number of subjects and/or the time frame, which will affect the power and the generalizability of the study. Although a larger number of observations increases the sample size, it may also add to the complexity of the analysis. Setting the time frame and time grid is therefore a complex issue that should be considered as integral part of the overall design of the research study (Buss, 1979; Collins \& Graham, 1991; Ettlie, 1977). Of course, the number of moments should be chosen in correspondence with the expected or postulated nature of the phenomenon (Collins, 1991; Mitchell \& James, 2001). For instance, when testing the validity of a four stage theory, there should be minimally four measurement moments (Ployhart et al., 2002).

Spacing observation moments over time, is a separate issue. Equally spaced moments are generally preferable in order to avoid statistical complications during the analysis, but unequal spacing is sometimes unavoidable. 
A specific way of handling the payoffs involved in setting the grid is to use a sampling approach to the timing of observations. Sampling may be a good answer to the threat of selectivity which is always present when decisions about the time frame and grid have to be made (Nesselroade, 1991). There are two aspects to consider. First, one may adopt a grid with fixed moments of observations but distribute the actual observations across these moments according to some probability function. Thus, one could throw a dice as to decide about which of six moments of observation to use when studying group interaction. This reduces the number of observations but increases the spread over the six observation moments. Secondly, one may use random rather than fixed moments of observations. In this way, there is a chance of detecting events that would otherwise fall between the lines of the grid. Both ways of sampling, which can clearly be applied together, have certain advantages when people are aware of being observed and might wish to impress the observer in a particular way.

\section{Observation and recording}

Not all methods used for data collection in cross-sectional studies are equally suited in temporal research. Methods relying on the self-description and judgment of people, such as interviews and questionnaires, have the disadvantage that repeated administration itself may influence their behavior and/or their judgment. Since these methods tend to raise subjects' awareness of the issues asked about, they may lead to enhanced reflection and impression management, and induce behavior changes or call for behavioral consistencies that would otherwise not have occurred. Many of these methods have another characteristic that make them particularly unfit for use in temporal research, i.e. the fact that they ask for generalized statements about perceived circumstances and behaviors. Thus, as mentioned before, the most commonly used questionnaires for assessing job and team characteristics, working conditions, leader behaviors, job attitudes and 
role behaviors, require respondents to endorse general statements about what happens while being at work, and leave little room to indicate changes.

What methods are then required to conduct temporal research? To avoid some of the effects of self-description one would need to rely more on methods that use professional observers and/or objective recording techniques. Since people may still be aware of being observed and hence respond to this, these methods should preferably be unobtrusive. Researchers in other disciplines have used a variety of methods which seem applicable to OB as well. Among them are: participant observation, repeated telephone surveys, video-recording, and the use of archival sources. Participant observation offers the possibility for continuing observation in a non-obtrusive manner. This allows for close spacing of observations. The method may be costly and take a long time before the data become available. Another potential disadvantage is idiosyncrasy of the findings as a consequence of observer influences on the object of study. Video-recordings can be used for generating time-series data

The measurement of subjective time is another issue, posing its own problems (Waller, 1995), the length of which can be controlled by the granularity of the time grid. Archival sources can be a useful source of data on employee careers, remuneration, performance etc. But they may offer additional opportunities for that have remained unnoticed so far. An example is the use of dated documents, such as agenda's and minutes of meetings, which contain rich information on OB-issues at all levels inside the organization. Some of these sources provide data on boundary spanning relationships with customers or members of other organizations. Such sources may be very useful in OB research provided that privacy and confidentiality issues are resolved.

The present availability of IT-infrastructure opens new possibilities for data gathering not known to researchers in the past. Objective and unobtrusive data may be extracted from electronic logs of internet and intranet sessions, e-mail and mobile telephone use (e.g. A. A. Cohen \& 
Lemish, 2003). If privacy issues are resolved, such data are attractive from a practical point of view since they do not require the researcher's presence and imply a reduced load of data coding.

Since self-descriptive methods may not be dispensed totally, they should be adapted as to make them more suitable for temporal research. Two types of adaptation are required: (1) they should gauge factual information about what happens, how the person feels, rather than on general judgments, and (2) the information should be linked to one or more particular moments in time. Thus, a statement like "In my job I can decide about what to do first", would be replaced by one or more statements of the following type: "Last week, I have decided about what to do first ... times." Or: "My boss usually asks our opinion before taking a decision" would be replaced by "Last week, my boss has ... times asked our opinion before he took a decision". Special techniques, known as experience sampling, may be used to provide subjects with triggers and to make them record current feelings or activities (e.g. Csikszentmihalyi \& Hunter, 2003).

Research that follows an 'insider perspective' requires methods that allow people to record their perceptions and actions with explicit reference to time. A well-known method is the diary method, which requires subjects to keep a record on particular experiences or behaviors, with respect to as specific time grid. A review of the methodological aspects and uses of diaries has been given by Bolger, Davis, \& Rafaeli (2003). Although diaries have the advantage of producing a time-based record of people's activities, there is the risk that keeping the diary interferes with activities that would otherwise occur, or has a structuring influence on the activities due to enhanced awareness and planning. Another method is one which relies on the temporal tools that people use in everyday worklife, i.e. personal planners, calendars and the like (Roe \& Quist, 2004). The method can be extended into the use of groupware-based work calendars (Lee, 2003). 
Most of the methods mentioned are suitable for making observations and/or recordings in a forward manner, starting from the beginning of the time frame. Some of them can also be applied in a backward manner, that is starting from some arbitrary point within the time frame or at the end of it. In that case data are generated by relying on existing records prepared for some other purpose (i.e. the case of archival data) or on human memory. In view of the limitations of human memory it is usually not possible to generate data on past events and behaviors without memory aids. Fortunately some memory aids are available and can be used for research purposes. Among them are the life history calendar (LHC) methodology and stimulated recall. In LHC analysis subjects are asked to report about their behaviors with reference to objective 'marker events' that have happened at a known point in time. Such 'marker events' could relate to societal events (e.g. 'September 11'), company events (the move to another location) or personal events (birthday). A description of LHC-methods and applications are given by Axinn, Pearce and Ghimire (1999) and Freedman et al. (1988). The method is suitable for anchoring well-recalled discrete behaviors on the time scale, even over larger time intervals, but not for retrieving routinelike behaviors and attitudes. Stimulated recall is a generic name for methods used to enhance the recall of behaviors and feelings by using recordings of people's own behaviors. Applications have been described by Dershimer and Conover (1989) and Stockton, Morran and Clark (2004). Stimulated recall is recommended to explicate behaviors and feelings that could not be verbalized when they occurred, because people were not fully aware of them or because verbalizing would have interfered with the ongoing action, or would have produced alternative lines of action. The method is less suited for application after long time intervals, since it assumes that active memory traces are still available when the person is confronted with the record. Applications in psychological studies have used intervals of hours or days. In OB-research one could perhaps look back at behaviors which have taken place a number of weeks ago, provided that the behavior 
was not too molecular. One could also think of the use of minutes of meetings in reconstructing decision making or conflict resolution processes.

\section{Measurement}

There are a few points to make about measurement in temporal research. These have to do with the measurement of time and the measurement of change in intensities or numbers. As for the measurement of time, it would seem that the selected time scale defines the way in which time is measured $^{12}$. Recurrent (ahistoric) time will be measured with reference to a clock, while historic time calls for measurement with reference to an 'eternal' calendar. The units of measurement will depend on the chosen resolution of the scale, and may range from minutes (or less) to decades (or more). For many OB phenomena at the individual level a single day might a useful unit (e.g. Fuller et al., 2003). For group or organization level based OB phenomena a unit of a eek or month may be more appropriate (Pearce, Stevenson, \& Perry, 1985a; Sawyer, Latham, Pritchard, \& Bennett, 1999). Although time is usually thought of as being measured on an interval or ratio scale, such an assumption is not necessary. As has been pointed out by Cliff (1991) meaningful temporal research may also be conducted with the help of ordinal time scales, which makes use of categories such as earlier-later, shorter-longer, before-after, and faster-slower. For the analysis non-parametric methods can be used ${ }^{13}$. Of course, the appropriate measure of time also depends on the way in which the time frame and time grid have been set. E.g. equally spaced moments of observations do imply the measurement of time at an interval level.

Temporal research also includes measurements of attributes or system states, such as the strength of an attitude, the degree of perceived strain, the level of performance, the accumulated number of errors and the like. However, the attributes may also refer to qualitative states or successive stages. Since the focus typically is on changes in such states or attributes, the measurement should be made on an appropriate scale. This may require the use of special scaling 
methods (Collins, 1991). A next requirement is that the scale is sufficiently sensitive to the magnitude of changes occurring. Thus, if changes are small the scale should have a fine resolution. Another requirement is that the reliability of the measurements is relatively high. This is especially important in change scores since the reliability of changes derived from two measurements is known to be substantially lower than those of separate measurements. However, the reliability cannot always be assessed in the way defined by classical test theory, since relevant score levels (e.g. scores near the high end of the scale in case of complete mastery) may produce a low variance and hence low correlations (Collins, 1991). Still another requirement is that the attribute itself is stable and does not change over time. Whether this is the case, and to which degree, is an intriguing issue for research. A method of investigating this is assessing the factorial stability of a set of variables (Cunningham, 1991). Research should identify whether the factor structure remains the same, or whether certain common factors and/or factor loadings change.

The measurement of change poses a specific problem. The often used option of calculating differences scores between repeated measurements is subject to a long lasting debate (Edwards, 1994; Rogosa \& Willett, 1983; Tisak \& Smith, 1994; Werts \& Linn, 1970). Their main limitation lies in a low reliability and the fact that they do not account for the autocorrelation between repeated measures. This problem can be avoided by using regression techniques to partial out the earlier scores from the later scores.

Issues in studying relationships between phenomena

Designs for studying the casual relationship between multiple phenomena, should follow the general logic of experience to establish the links between independent and dependent variables while applying controls ${ }^{14}$. A number of issues should be dealt with in making the appropriate designs. First, there is the issue of assessing sequence. When looking for causal links it is important to establish "what comes first". Thus, the it should possible to ascertain whether 
phenomenon A actually precedes phenomenon B. However, since many OB phenomena recur and overlap in time, the focus has to be on the timing of a particular instance or cycle of A in comparison to an instance or cycle of B. This will require a closely spaced time-grid, because wide spacing does not allow the researcher to discriminate between subsequent instances and cycles of both phenomena.

A second issue is that of delay. Temporal research studies must take into account that there is always a delay between the occurrence of the cause and the effect ('causal lag', 'effect period'). Thus, a delay factor of appropriate magnitude has to be part of the design. This calls for moments of measuring the independent and the dependent variable that are sufficiently distant in timeBut in addition, the delay should be modeled in method of analysis. E.g. when analyzing lagrelations in time series, lags of appropriate length must be chosen. What is sufficient and appriopriate has to be ascertained by descriptive research.

A third issue is control. Like in traditional research the research design should rule out alternative explanations of the dependent variable. In temporal research it is important to rule out the possibility that concomitant phenomena are interpreted as causal determinants. This calls for the inclusion of variables reflecting potential concomitants in the design of the study as control variables. Other threats to internal validity are posed by non-measured phenomena occurring during the time intervals that separate the measurement of independent and dependent variables, and/or repeated (obtrusive) observations. A special problem for control is posed by compound effects, or 'time-lagged multicausality' (Nesselroade \& Baltes, 1979; p.37). This means that multiple causes become operational at different moments in time. For example, the dependent variable may reflect the influence of cause $A$ during period $t_{A}$ and of cause $B$ during period $t_{B}$ where $t_{B} \neq t_{A}$. In such a case A and B should be modeled as casual determinants in the design of 
the study, or B should be treated as covariate, taking the different exposure times into account. Effects like these turn the design of temporal studies into a difficult task.

\section{Methods of analysis}

In order to facilitate the choice of methods that are suited for answering the three main types of research distinguished before, this section provides an overview of seven methods for temporal analysis. Table 2 lists the methods and indicates for which research purpose they might be applied.

Here table 2

We will first discuss Descriptive Modeling and Random Coefficient Modeling, the application of which is limited to temporal modeling, that is, to identifying the form of development displayed by a phenomenon. Next, we will discuss Latent Growth Modeling and Even History Analysis which are suitable for temporal modeling as well, but can also be used for the analysis of temporal relationships. Subsequently, we will discuss Time Series Analysis, which is most versatile and can be used for modeling, analyzing temporal relationships, and assessing long-term constancy. And finally, we will look at analysis of variance and regression analysis as generic methods that might be used for the assessment of long-term constancy in conditioning research.

We will described the logic of the analysis and refer to methodological sources providing formal descriptions of the methods as well as examples of studies in which they have been applied. Whenever available we will mention applications in organizational settings, otherwise applications from areas such as economics, medicine, and developmental psychology in which these methods were developed and. widely applied.

There are other methods for temporal analysis, such as Dynamic Systems Modeling and Non-Linear Dynamic Modeling which are suited to study phenomena of greater complexity than those addressed in this article, that is, multi-attribute phenomena, interactions between multiple 
actors, and multi-level relationships. We will briefly refer to these methods when discussing future challenges in temporal research in the next section.

\section{Descriptive modeling}

A straightforward approach to model changes of an attribute over a certain time interval is to plot the observed values as a function of time and to apply curve fitting methods to identify functions that capture the essential features of the resulting graph. This approach has been used on a wide scale in sciences such as biology and psychology, which have a great interest in understanding growth and change (McArdle, 2001). Next to basic linear functions researchers have used polynomial, exponential, logistic, and ogive functions. While linear functions may be acceptable as rough approximation of change, non-linear functions tend to provide a better fit. A number of highly flexible functions have been identified that can model a wide range of other phenomena, including those showing seasonal shifts. Examples are exponential and power functions, the Gompertz-curve, etc. Methods of curve fitting are of importance for temporal research since they provide parameters (concerning onset, duration, upward or downward slopes) that may be used in subsequent explanatory research.

An important point of concern in curve fitting is the risk of capitalization on chance, which increases with the number of parameters of the function. Choosing the right type of function and minimizing the number of parameters is therefore an important objective. The risk of capitalization on chance can be reduced by data reduction, e.g. by establishing principal components of the repeated observations and using the component scores to establish 'latent growth curves'. This approach will be discussed below (see: Latent Growth Analysis).

With phenomena revealing themselves in discrete states (e.g. events) rather than levels on a continuous scale, such quantitative approach cannot be applied. Here a form of modeling is required which records the transition of one state to the other and the moment in which this 
happens. An interesting illustration is provided by a study of (Seeley \& Targett, 1999) in which changes in the degree of computer use by managers are depicted and shown to constitute different paths over time.

Since individuals (similarly: groups, organizations) differ in the pattern of change displayed over time, descriptive temporal modeling must find a way to deal with individual differences. A traditional approach is to apply curve fitting to the time series data of every individual and to algebraically average the curves as to show the overall pattern of change (Burchinal \& Appelbaum, 1991; McArdle, 2001). However, when there are differences in individual curves averaging is less meaningful. Another approach is to fit the curve to the data of all individuals simultaneously and evaluate the variance of each individual's residuals, as happens in modern methods based on hierarchical linear modeling. Unless the dynamic features of phenomena are already well-established, researchers may follow another approach that helps to explore these features and the factors on which they depend. For this purpose one might resort to cluster analysis and group the individuals on the basis of their change pattern. There are various ways in which this can be done, depending on the structure of the data and the clustering algorithm An interesting way to visualize and cluster data which were obtained with reference to a (daily \& weekly) calendar has been proposed by Van Wijk \& Selow (1999), using data from an Dutch energy supply firm. First, two dynamic phenomena (examples were: electric power demand and presence of number of employees) were visualized with reference to hours of the day and days of year. Next, the days were clustered so that - at different levels of cluster strength - groups of similar days are produced. Subsequently, the clusters were compared with respect to the (averaged) patterns and explanations for differences can be generated. Reference information from the calendar appeared to be most helpful in this case and helped to generate explanations for 
the various different patterns found. The specific method seems of interest for use in OB research since a great deal of human behavior in organizations is structured according to the calendar.

\section{Random coefficient modeling (RCM)}

A method for longitudinal analysis with growing popularity in organizational research is 'random coefficient modeling' (RCM). This is an application of Hierarchical Linear Modeling to cases in which there are multiple measurements on the same objects (Bryck \& Raudenbusch, 1987; Ployhart et al., 2002). The measurements are supposed to display a linear change process characterized by two parameters, i.e. intercept and slope, reflecting the initial level at the beginning of the time interval and the rate of change (e.g. growth, learning). Following Goldstein (1998) the basic model of RCM is the following:

$$
\mathrm{Y}_{\mathrm{ij}}=\mathrm{b}_{0 \mathrm{j}}+\mathrm{b}_{1 \mathrm{j}} \mathrm{t}_{\mathrm{ij}}+\mathrm{e}_{\mathrm{ij}} \quad \text { (level } 1 \text { model) }
$$

where $\mathrm{i}=1, \ldots, \mathrm{T}$ measurement moments, $\mathrm{j}=1, \ldots ., \mathrm{N}$ subjects, and $\mathrm{t}_{\mathrm{ij}}=$ time.

That is, for each individual the observed score of the attribute $Y_{\mathrm{ij}}$ is conceived to be the sum of the intercept $b_{0 j}$, the product of slope $b_{1 j}$ and the coded time code $t_{i i}$, and an error term $e_{i j}$. The intercept and the slope are allowed to vary (randomly) across individuals. Thus, they can be considered as the common intercept $\left(\pi_{00}\right)$ and slope $\left(\pi_{10}\right)$ of all individuals plus an individual error term $\mathrm{r}_{0 \mathrm{j}}$ and $\mathrm{r}_{1 \mathrm{j}}$ ), or:

$$
\begin{array}{ll}
b_{0 j}=\pi_{00}+r_{0 j} & \text { (level } 2 \text { model) } \\
b_{1 j}=\pi_{10}+r_{1 j}, &
\end{array}
$$

This model can be seen as a multilevel regression model with two levels, were the measurement moments (or the factor time) represent level 1, and the individuals represent level 2. In the analysis the fixed effects of time are evaluated first, the random effects of individual variations second. 
It is possible to extend the model in two different ways. Higher order terms may be added as to produce a non-linear function that better fits the data. We refer to the paragraph on curve fitting above. A useful alternative is the power function which only has two growth parameters, just like the basic linear model (see Ployhart et al., 2002):

$$
Y_{i j}=b_{0 j} \cdot t_{i j}^{b l j}+e_{i j}
$$

In addition, variables may be added which can predict the individual growth parameters. These variables are added to the level 2 model; for instance:

$$
\begin{aligned}
& b_{0 j}=\pi_{00}+\pi_{01} X_{1 j}+\pi_{02} X_{2 j}+r_{0 j} \\
& b_{0 j}=\pi_{10}+\pi_{11} X_{1 j}+\pi_{12} X_{2 j}+r_{1 j}
\end{aligned}
$$

Although it is customary to think of $X_{1}$ and $X_{2}$ as stable characteristics, such as personality traits, one might as well use parameters describing temporal phenomena. This makes the RCM method suitable for the analysis of temporal relationships as outlined earlier in this article.

RCM is enjoying increasing interest among organizational researchers. The chapter by Ployhart et al. (2002) gives a very accessible description of the method for leadership researchers as well as an application to leaders' adaptability to team development. Changes in leader performance over four quarters are modeled with a quadratic function and differences in adaptability between individual leaders are explained from the personality factor agreeableness. In a study by Russell (2001) RCM has been used to predict the development of managers' performance, as assessed by various measures, from early competency ratings. Using linear functions to model performance trends, it was established that different competencies predict the initial level and the slope of the performance trends. Other examples of applications to organizational settings, involving citizenship behavior, procedural justice and safety, can be found in Biese (2002), who also demonstrates how RCM should be applied. 
More extensive treatments of RCM can be found in Laird \& Ware (1982), Bryck \& Raudenbusch (1992), and Hofmann (1997). It should be noted that RCM, like other methods of longitudinal analysis is vulnerable to a number of threats, which have to do with missing scores, unequal spacing of measurement moment, and error covariances. Another issue of concern is time coding: it has been shown that different ways of coding time (e.g. respondent's age) may affect the estimation and interpretation of growth curve trajectories (Biesanz, Deeb-Sossa, Papadakis, Bollen, \& Curran, 2004). These issues should be carefully considered when designing the study.

In conclusion, it seems that RCM modeling is a useful method when it comes to modeling temporal phenomena, although linear and other commonly used functions may not be appropriate to model larger segments of the life cycle of phenomena as proposed here. RCM can also be applied in research on temporal relationships between phenomena by using selected parameters of the function that describes the antecedent phenomenon as predictors in the random part of the model.

\section{Latent growth modeling (LGM)}

Latent growth modeling (LGM) is related to RCM and produces similar results. It uses structural equation modeling techniques rather than hierarchical regression, however. The basic idea of the method is similar to that of factor analysis, that is, the scores of individuals in a time series can be reduced to two (or more) underlying factors, often labeled initial status and rate of change. These factors represent the intercept and the slope (possibly higher order terms) of the growth functions that best fit data (see Figure 6).

\section{Here Figure 6}

Due to the use of structural equations modeling, this method offers a number of interesting features. First, a model can be built with includes one or more predictor variables, that is, variables predicting initial status and growth rate. In this respect the method is similar to RCM. 
Secondly, latent variables with corresponding measurement models can be introduced. This is an important extension, since it enables the researcher to test the measurement equivalence of serial measurements, which is an important precondition for the analysis of change (e.g. Lance \& Vandenberg, 2000). Third, the method allows the analysis of multiple latent growth functions together. Thus, two attributes of the same phenomenon can be included as to produce an integrated model of change with specified links between the intercepts and slopes of the latent growth functions for these attributes. This opens the way to the study of patterns of development (see future challenges in section 7). Similarly, the intercepts and slopes of distinct phenomena may be interrelated. This makes the method suitable for the analysis of temporal relationships, e.g. between the dynamics of commitment and turnover. More specifically, the parameters of the growth functions of two phenomena can be linked to each other. An additional strength of LGM is the opportunity to model specific error covariance structures, which is important in the analysis of longitudinal data.

Again there are some limitations, much like in RCM (Chan, 2002). LGM cannot be applied to categorical variables, it requires relatively large sample sizes, and it is sensitive to selective nonresponse, unequally spaced measurement moments, which researchers should be alert to (Davey, Shanahan, \& Schafer, 2001). Unlike RCM the LGM method does not explicitly use time as a variable in the model and therefore does not account for interactions between time and other predictors. Recently an extension of LGM has been proposed that overcomes this limitation (Curran, Bauer, \& Willoughby, 2004).

Introductions to LGM can be found in Chan (1998; 2002) and Rudinger \& Rietz (1998). More extensive treatments are given by Meredith \& Tisak (1990), Stoolmiller (1995) and Willet \& Sayer (1994). LGM had been widely applied in educational and developmental research (e.g. Chan, Ramey, Ramey, \& Schmitt, 2000; Chisletta \& McArdle, 2001; Reddy, Rhodes, \& Mulhall, 
2003; Stoel, Peetsma, \& Roeleveld, 2003). Applications in the OB-field are still rare. An exemplary study is that by Lance and Vandenberg (2000),who used LGM to investigate changes over time in three dimensions of commitment during the first six months of work, using a model including measurement models for these dimensions. It was found, among others, that the decline in internalization could be predicted from antecedents (anticipatory met expectations and jobchoice decision difficulty) and was itself predictive of turnover intention.

It seems that LGM is a useful method for temporal modeling as well as for analyzing temporal relationships. The possibility to model multiple attributes of the same phenomenon or attributes of separate phenomena simultaneously is particularly attractive for the study of $\mathrm{OB}$ dynamics. E.g. the possibility to relate the initial level or slope of phenomenon A to the initial level and slope of phenomenon B fits very well into the analytical scheme that was proposed in section 4.2.2. The major limitation we see is that the growth functions that can be studied with LGM cover a more limited segment of the life cycle of the phenomena under study than we consider to be relevant.

\section{Event history analysis (EHA)}

The method known as Event History Analysis (EHA) has a long history in disciplines such as demography, medicine, biology, engineering and economics. It is also known as Survival Analysis, a name which refers to the study of people's decreasing chance of being alive at successive moments in time. In EHA the phenomenon under study is not continuous but discrete; it is an 'event' or 'change of state' that normally happens only once at a moment that varies across individuals (groups, organizations). Examples of such events at the individual are promotion, entry into unemployment and retirement. In the context of team development events might be transitions between stages. In the radical temporalist perspective these events represent seemingly timeless phenomena, that is, without a duration, which makes them less interesting to study. 
However, one might also look at the event as a marker of the onset of a phenomenon (or the end, or a critical point in its development such as its lowest or highest level). The fact that EHA focuses explicitly on the moment (i.e. the location at the time-line) in which the event takes place, makes it an interesting methodological tool next to other methods which fail to take this aspect into consideration.

EHA uses time data showing the moment in which a transition between states or events occurs. The analysis aims at predicting the likelihood that the event will occur on a particular moment and/or the time to the event (i.e. the moment in which the event is likely to take place) (Allison, 1984; Kiefer, 1988). These predictions may be based on a many different types of predictor variables. Among them are discrete as well as continuous variables that are either timeindependent or time-dependent. In the context of the present article, with its focus on temporal phenomena, time-dependent variables are clearly of greater interest. Examples of such variables are: job level, employment status, nationality (discrete); age, tenure, skill level, income (continuous). Examples of time-independent variables are: gender (discrete), ability, personality traits (continous). EHA allows to estimate the main effects of such predictors as well as their interactions.

EHA is based on an analysis of the 'hazard rate', i.e. the odds that an event will occur given that it has not already occurred at a particular moment in time. The 'hazard function' shows this hazard rate for different moments in time. EHA offers the possibility to choose different types of hazard functions depending on the nature of the data (measurement of time as discrete or continuous) and the distribution of events over the time interval (e.g. constant or increasing in frequency). Which functions are to be preferred differs across areas of study. In organizational research there is a preference for semi-parametric models, which do not assume a particular form 
for of the hazard function (Smith \& Tonidandel, 2003). An example is the so-called 'proportional hazards rate model' (Cox, 1972):

$$
\log h(t)=a(t)+b_{1} X_{1}+b_{2} X_{2}+\ldots .+b_{n} X_{n}(t)
$$

in which $h(t)$ is the hazard rate and $a(t)$ is an intercept representing the base-line hazard rate as a function of time only. Various predictors, $X_{1}, X_{2}$ etc., some of which possibly time dependent, may affect the hazard rate beyond this level. A graphical representation of two hazard functions, taken from the study of Smith \& Tonidandel (2003), and representing the hazards of promotion for attendees and nonattendees of a leadership development program, is given in Figure 7 below. EHA offers a wide range of modeling options. First of all, there are several functions for modeling the hazard rate. In addition, it is possible to model recurrent instead of singular events (e.g. re-entry into unemployment). Another option is to model competing events (e.g. either career choice A or B).

\section{Here Figure 7}

Like other methods, EHA is sensitive to missing and incomplete obervations. There are two cases of incompleteness which may affect the estimation process. In "right censoring" the event falls out of the time window of the study, in "left censoring" the antecedent data are lacking. Unless censoring can be assumed to be independent from the time at which the event happens, this results in biased results. Special techniques are needed to correct for such effects (Allison, 1984; Parmar \& Machin, 1995). Another issue is unobserved heterogeneity, that is, a sample may contain subsets for which the hazard rate is different. For instance, the sample may contain a subgroup with higher chance of promotion. Preventing or detecting such differences is important to prevent biased results.

There are several good introductions to EHA (Luke, 1993; Parmar \& Machin, 1995; Wright, 2000). More extensive treatmens are given by (Allison, 1984; Wright, 2000; Yamaguchi, 
1991). A basic introductions to EHA can be found with Smith \& Tonidandel (2003), who also give a hypothetical example for the domain of leadership research. In this case cognitive ability and participation in leadership training are used to predict the promotion of individuals to an upper management level at various moments in time, using logistic regression. There are several applications of EHA in the organizational domain, many of which relate to employee turnover (Dickter, Roznowski, \& Harrison, 1996; Hom \& Kinicki, 2001; Iverson \& Pullman, 2000; Somers \& Birnbaum, 1999; Trevor, 2001; Walker, 1999) and career transitions (Boeker \& Karichalil, 2002; Judge \& Watanabe, 1995; Koenigsberg, Garet, \& Rosenbaum, 1994). Outside of the organizational domain EHA has been applied to a wide range of phenomena, especially in demography, medicine and economics.

How useful is EHA in the analysis of temporal phenomena? On the one hand the usefulness of the method is limited because the events are essentially timeless and do not possess characteristics of duration and dynamics. But on the other hand, it measures and estimates durations until the moment of occurrence (a point on the time scale; cf. effect period), a feature that is lacking from the methods that were discussed above. It would seem possible to conceive of events as markers of specific features of dynamic phenomena rather than as phenomena in their own right. Such markers could define the beginning and the end of the phenomenon, and perhaps specific reference points such as the highest or the lowest point of the curve describing the event, provided that these are theoretically meaningful and lead to measurement properties that are compatbible with the assumptions of EHA. This would make EHA a useful method in the research toolbox for temporal analysis as defined in this article.

\section{Time series analysis (TSA)}

The term Time Series Analysis (TSA) refers to a set of methods that aims for modeling and analyzing the dynamic structure of a single (univariate) series of observations and the 
relationships among several (multivariate) series of observations (Box, Jenkins, \& Reinsel, 1994; Ostrom, 1978; Pena \& Tiao, 2001). The observations should be obtained from measurements at equally spaced intervals. The method is based on regression in a time series of observations (autoregression). Thus, an observation at moment $t$ (measured on a continuous scale) is predicted from observations made on earlier moments, e.g. $t-1, t-2$, etc. Typical examples from the domain of economics, in which TSA has found widespread application, are: daily exchange rates, weekly sales volumes, monthly unemployment rates, yearly investments. The basic function in TSA is:

$$
z_{t}=f\left(z_{t-1}, \ldots ., z_{1}\right)+a_{t}
$$

where $f\left(z_{t-1}, \ldots, z_{1}\right)$ is based on past values and $a_{t}$ is a random noise (error) part (Pena \& Tiao, 2001). Since dynamic phenomena can have all sorts of shapes (e.g. positively accelerated growth, or seasonal fluctuations with slow upward or downward trends), modeling the time series function $f$ is an important part of the TSA. Therefore curve fitting is a standard component of TSA, and various models have been developed for dealing with seasonal and trend components (Gardner, 1985).

Assumptions about the data lead to different types of analyses. An often made assumption is that of stationarity of the data, which means that there is a regularly recurring pattern of variation with a constant mean and variance. Non-stationarity, on the other hand, implies changing means (e.g. linear or non-linear trends) and changing variations (heteroscedasticity). Daily performance rates or seasonal turnover rates of employees might be stationary, whereas the incidence of absenteeism or conflict during a downsizing period, might be nonstationary. Another important assumption in TSA relates to the role of earlier observations, or the "memory" of the time series. For certain phenomena it would be reasonable to assume that the memory is limited to the preceding observation (e.g. the previous day) while for others there it would make sense to 
expect effects of a long range of earlier observations. Several specific techniques for weighting earlier observations exist.

A common technique is known as linear autoregressive integrated moving-average or ARIMA model (Box et al., 1994). Here the function $f$ has a linear form and can be written as:

$$
f\left(z_{t-1}, \ldots, z_{1}\right)=\phi_{1} z_{t-1}+\ldots+\phi_{t-1} z_{1}
$$

where $\left(\phi_{1}, \phi_{2}, \ldots\right)$ are autoregressive parameters (Box et al., 1994; Pena \& Tiao, 2001). An

assumption of the ARIMA model is that each observed score in the series is also dependent on past errors as well as the current error. This explains the moving-average in the model.

When multiple time series are present, assumptions have to be made about their interrelations. Such relations can be either unidirectional or bi-directional (feedback). In the case of consumer price and sales volume, a unidirectional relation might be assumed: when the price goes up, sales goes down. An example from the field of $\mathrm{OB}$ is the relationship between employee workload and absenteeism (e.g. number of days absent). However, with regard to this example one might also make an alternative assumption, i.e. that absenteeism would produce a higher workload at a later moment. Such feedback relations may be quite prevalent in OB. Multiple time series allow the prediction of one time series from one or more others.

A key issue in making predictions is the time lag (cf. delay), between a change in the one series and a change in the other series. With a wrongly chosen time lag two phenomena may seem unrelated, while the "proper" time lag may demonstrate a strong relation. Another important issue is to decide which time series predicts which other time series, especially in the case of feedback between two or more series.

In multiple time series one builds a dynamic regression equation of the type:

$$
y_{t}=g\left(x_{t}, \ldots, x_{1}\right)+f\left(y_{t-1}, \ldots, y_{1}\right)+a_{t}
$$


which can be generalized into a multivariate time series model

$$
\mathbf{z}_{t}=\mathbf{f}\left(\mathbf{z}_{t-1}, \ldots, \mathbf{z}_{1}\right)+\mathbf{a}_{t}
$$

in which $\mathbf{z}_{t}$ is a vector of $k$ related time series, $\mathbf{f}$ is a vector of past values of all components to be determined from the data and $\mathbf{a}_{t}$ is a sequence of vector variables not dependent on any lag (Pena \& Tiao, 2001). When $\mathbf{f}$ is supposed to be linear, this produces a multivariate ARIMA model. The multivariate model is equivalent to $k$ dynamic regression equations in which each series is explained as a function of the past of all other series and its own past.

While widely applied in economic research, the use of TSA in organizational research has remained rather exceptional. Yet, there are several interesting examples in this domain. Bernhardt, Donthu, \& Kennett (2000) examined the performance of restaurants in relationship to customer and employee satisfaction over a 12 month period. While no relationships could be established in the short run, customer satisfaction was related to restaurant performance in the long run. In a recent study Fuller, Stanton, Fisher, Spitzmuller, Russell and Smith (2003) investigated the relationships between daily stressful events, mood, strain and satisfaction among 14 university employees, over a period of 14 (up to 18) weeks days. The influences of stressful events on strain and satisfaction were investigated. Both short term strain responses and long term trends in strain were identified. Swayer, Latham, Pritchard, and Bennett (1999) applied TSA to study the effect of priority feedback (priority $=$ the effectiveness gain from a single unit increase in a productivity indicator). Some studies have used TSA to study the impacts of interventions such as the effects of introducing an incentive system on productivity (e.g. Pearce, Stevenson, \& Perry, 1985b; Wagner, Rubin, \& Callahan, 1988), the effects of Organizational Development on employee timeuse (Miners, Moore, Champoux, \& Martocchio, 1994), or the effect of a behavior modification 
program on employee attendance (Beard, Woodman, \& Moesel, 1998). In the latter study the effects of seasonal, holiday, weather-related and widespread illness were corrected for.

The potential for using TSA in the field of OB is large. In fact, it is one of the most powerful methods to investigate dynamic phenomena and their temporal relationships. Its modeling capabilities and analytical options reach way beyond random coefficient and latent growth models. One of the advantages of TSA that it allows the researcher to identify 'transfer functions' (Box et al., 1994) which specify the way in which changes in one (e.g. antecedent) phenomenon affect the dynamics of another (e.g. focal) phenomenon, which is one of the key issues in research on temporal relations. In principle, TSA might also be applied to examine the constancy of dynamic patterns and interrelationships over longer terms, just like this has been done in economics where series of interests rates, stock prices or real estate prices have been collected over decades and analyzed for patterns and interrelationships. An interesting example from the behavioral sciences is a study by Meloen (1983) mentioned before. He gathered data on student authoritarianism from US studies in the period 1954-1977 and predicted the trend from changes in social and economic indicators. Using an index of authoritarianism constructed from indirect measures he did a similar analysis over the interval 1920-1977. Similar applications of TSA in the field of OB are certainly feasible. The main impediment is of a practical nature, i.e. to collect sufficiently long time series data from organizations and employees.

\section{Analysis of variance (ANOVA)}

Analysis of variance (ANOVA) is the most used method in connection with longitudinal (quasi)experimental designs that compare a few measurements taken at distinct moments in time. However, this application of the method provides little information on time or on the dynamic aspects of the phenomena under study. ANOVA can also be utilized to study temporal relationships and long-term constancy. Repeated measurement models are suited to establish the 
linear effects of time and the effect of one or more discrete factors such as events or states. For example, one might apply this kind of analysis to time-series data on the commitment of employees exposed to types of motivational interventions. The analysis would show the main effects of time and the intervention factor, as well as their interaction. Due to the assumption of linear effects, a repeated measures analysis is rather limited in its capability for temporal; modeling.

A more powerful use of analysis of variance is possible with factorial designs in which the dependent and independent variables represent specific parameters of dynamic functions that have been established beforehand. For example, the dependent variable might be the duration or the growth rate of a focal phenomenon, while the independent variables could relate to parameters of an antecedent phenomenon. One might e.g. apply a $2 \times 2$ factorial design in a study in which the growth rate of commitment (dependent variable) is studied in function of the adjustment of initial expectations (low, high) and the onset of the first career change (early, late). The parameters involved in such analyses can either be measured (such as moment of onset, or duration), or be established by means of descriptive modeling, random coefficient modeling, latent growth modeling, or other analytical approaches. Another type of application of ANOVA is in temporal conditioning research, where parameters from different époques can be compared. A possible application in this context lies in cohort analysis (Glenn, 1977). Here the differences between successive measurements are separated from generational differences.

Although analysis of variance is restricted by its assumptions of linear relationships and homoscedasticity, it is a versatile methodology with many possible applications, including multiple dependent variables. 


\section{Multiple regression analysis (MRA)}

Multiple Regression analysis underlies specific methods for temporal modeling and analyzing relationships between temporal phenomena, such as RCA and TSA, that have been described before. However, regression-analysis can also be used to analyze the relationships between parameters of one or more phenomena. For instance, to mention a case of two phenomena, one might regress the duration of individual sickness leave on the decline of individual satisfaction (as expressed by a regression coefficient obtained form an individual time-series). Just like with analysis of variance, all combinations between dynamic aspects of OB-phenomena discussed earlier, may be investigated in this way. MRA may also be used to assess stability or change over longer time periods. Meta-analysis can be considered as such an application. Cohort effects can be examined by means of dummy variable regression.

Although based on the same model as, regression analysis differs from ANOVA in that independent variables are supposed to be continuous. Also it is assumed that the conditional probabilities $\mathrm{Y} \mid \mathrm{X}$ are normally distributed.

There are many possibilities to use MRA in temporal analysis. In longitudinal designs with a limited number of measurement moments, it has been applied in so-called 'cross-lagged panel analysis'. Somewhat similar is 'dynamic causal modeling', that is, the use of structural equations modeling involving measures from different measurement moments.

\section{Future challenges}

The implications of the radical conceptual and methodological reorientation that has been proposed in this article are far-reaching. First of all, it will take considerable scholarly effort to suppress the tendency to look at organizational realities in terms of variables and instead to adopt a view in which really everything happening has a limited life-span and a dynamic course. But turning the temporalist alternative into research designs and conducting empirical research studies 
calls for a formidable effort as well. Whether all this has sufficient appeal on OB researchers, whether it is feasible in terms of resources and time required, and whether it will have the impact aimed for, is something the future will tell.

\section{Surmounting practical hurdles}

A first challenge to meet is to surmount the hurdles that have hampered the development of temporal OB in the past. Dekimpe and Hanssens (2000), in an article on research in marketing, mention four obstacles that have hampered the use of time-series methods: "(1) marketing scientists' lack of training in TS (time series) methods and access to friendly TS software, (2) a resistance to data-driven approaches in model specification, (3) a lack of adequate data sources, and (4) the absence of a substantive marketing area where TS modeling was adopted as primary research tool" (op cit., p184-185). Although, these factors seem applicable to the field of organizational research as well, we believe there is some ground for optimism with regard to then future. First, the number of time-based studies in the field is slowly increasing. Also, there seems to be a growing interest in disseminating time-based methods in the OB-field (see for instance the special series of articles in Leadership Quarterly). Second, while OB researchers may indeed be reluctant to accept data-driven approaches and to prefer to depart from existing theoretical models, but they will increasingly recognize that models which fail to specify temporal aspects will continue to give meager descriptions of reality and remain largely inconsequential. It may also be expected that the application of temporalist thinking to existing models will result in a new generation of models that can guide further research. Third, the lack of data sources may remain a serious impediment to temporal research, the prime reason being that gathering timeseries data is costly and that managers and employees have difficulty seeing its benefits. However, studies such as by Sawyer et al. (1999) on the utility of productivity feedback, or by Fuller et al. (2003) on the development and impacts of stress, demonstrate that it is possible to 
obtain firms' cooperation if the research aim is seen as relevant. In addition, researchers may find ways to generate time-series from sources that do not require time-consuming response gathering techniques. For instance, time-series may derived from existing objective or archival data by using extended time-intervals. Using video-recordings or internet-data in combination with a fine time-grid sufficiently long time-series may be constructed as well (Dekimpe \& Hanssens, 2000). Fourth, the absence of an area in which methods of temporal analysis find natural application may appear to be least important, when the other factors can be addressed. In fact, there are several areas where methods of temporal analysis, once available, would make perfect sense.

Performance management, stress management, career development, leadership development, team development, organizational change, are all examples of areas which would profit from temporal research.

\section{Broadening the scope}

A second challenge is to widen the scope of the temporalist view as proposed in this article. For reasons of simplicity, we have restrained ourselves to a rather narrow set of conditions, i.e. we have confined ourselves to the dynamics of similar entities at one single level (i.e. individuals, groups or organizations), and to phenomena that vary with respect to a single attribute only. However, there is no compelling reason to stick to this limited conceptualization. Three types of extensions are conceivable. First, one might broaden the scope of the study to the relationships between multiple entities at the same level. For example, instead of the change of individuals one might focus on the change in the relationships between $k$ individuals. A dynamic analysis would then cast light on the interaction and changing interrelationships between individuals, and it would clarify the emergence, consolidation and change of patterns of social interaction. In this way, one might e.g. study the emergence and decline of friendship ties within teams, or flows of knowledge between team members. Second, by defining the links between entities at different 
levels (e.g. by nesting individuals within groups, and groups within organizations) a multi-level structure with three levels might be created. Dynamic analysis with the aid of hierarchical linear modeling would clarify the relationships between individuals and groups, between groups, between individual members of different groups, between groups and organizations. In this way dynamic aspects of the informal social structure in an organization might be studied. Third, phenomena might be defined to have $m$ attributes rather than one attribute. This would not only lead to a richer description of the phenomena but also create the possibility to study its dynamics in multiple attributes at the same time. Imagine, for instance, that the phenomenon of leadership would be defined with regard to multiple stylistic and behavioral aspects at the same time. Time series analysis would make it possible to identify various patterns of leadership and these would be characterized by dynamic rather than static features.

\section{Dealing with methodological complexities}

While these extensions are most exciting from a theoretical point of view, and perhaps promising from a practical perspective, it must be acknowledged that the research methods required to study them are very complex indeed. Another major challenge therefore is to develop research methods which are suited for modeling and analyzing these more complex representations of the organizational reality. In taking up this challenge researchers might profit from other methodologies than those already mentioned, including non-linear dynamic modeling and dynamic systems modeling. In non-linear dynamic modeling (NLD), commonly known as 'chaos theory', the phenomenon is represented as a changing state of a system, defined with regard to multiple dimensions, and data on this change are analyzed to non-linear, including catastrophic changes. NLD methodology is particularly interesting because of its capacity to predict nongradual changes, such as the breach of the psychological contract, absenteeism, turnover, conflict 
escalation in negotiations, or the appearance of faultlines in groups. A good introduction to NLD and its applications to the domain of work an organization has been given by Guastello (1995). In dynamic systems modeling (DSM), also referred to as computational modeling, one defines a system comprising multiple components and/or dynamic variables that interact in transforming an input into an output. Computer simulation is used to generate various possible system states and to estimate outputs, given certain inputs. This is useful in determining complex interactions with non-linear consequences. Applications of DSM to behaviors in organizational settings have been compiled by Ilgen and Hulin (2000).

\section{Conclusions}

Although many authors have plead for the incorporation of time in organizational research and theory development, time is still underrepresented in current $\mathrm{OB}$. While time is salient in almost all aspects of organizational life, our knowledge about temporal aspects of employee and managerial behavior is very limited and fragmented. Basic evidence about the duration of phenomena, their rate of development and decline, long term trends etc. are lacking, and virtually no knowledge is available on the temporal aspects of causal relations. The increasing use of longitudinal designs does little to alter this situation, as they focus on causality rather than on the measurement of time.

The limited attention for time among researchers may partly be explained from difficulties in obtaining time-series data and the lack of familiarity with methods for temporal analysis. A more plausible explanation is that time is poorly represented in the concepts and models of OB theory, as a result of a pre-occupation with 'variables' and a confusion of variation between entities (individuals, groups, organizations) with variation within entities. To break the static way of thinking resulting from this approach, we propose a 'radical temporalist approach' in which variables are replaced by inherently dynamic phenomena. The focus on phenomena, the 
assumption that they are temporally bounded, and their characterization in terms of an onset, duration and dynamic course give temporal facets the greatest possible salience. This should facilitate research aiming at descriptive modeling of OB-phenomena, which has almost completely been lacking in the past. By addressing the links between any pair of phenomena (e.g. antecedent - focal, focal - consequent) we have been able to distinguish between nine prototypical problem types, which cover different aspects of temporal relationships and greatly enrich the common view of causality. The adoption of a wider notion of time, comprising long periods and historic époques, opens an additional research perspective which focuses on the generalizability of findings on particular phenomena, thereby expanding the visibility of temporality even further.

Our review of the methodological literature does acknowledge the difficulties in conducting research on temporal aspects of $\mathrm{OB}$, but it also convincingly shows that there are several methods which researchers can employ in answering the multifaceted questions stemming from the radical temporalist perspective. This applies to general methods of research design, covering issues such as the time scale, time frame, time grid, observation/recording, and measurement, as well as methods of analysis, such as descriptive modeling, random coefficient modeling, latent growth modeling, event history analysis, time series analysis, analysis of variance, and multiple regression analysis. As these methods have been successfully used by researchers in other disciplines, and in several cases also by organizational researchers, there is no reason why they should not be applied in future OB research.

The proposed approach is not without difficulties or limitations, and there are several challenges, relating to practical hurdles, broadening the theoretical scope by incorporating multiple entities, levels and attributes, and dealing with methodological complexities to be met in future work. 


\section{Footnotes}

${ }^{1}$ We confine ourselves to the study of single phenomena but acknowledge that multiple phenomena can covary and constitute compound behavioral patterns. For example, a organizational commitment, job satisfaction, turnover inclination, and organizational citizenship behavior might form a consistent pattern that develops as a whole and declines, or perhaps disintegrates, when conditions deteriorate.

${ }^{2}$ This implies that meta-analyses as commonly conducted (e.g. Ones, Viswesvaran, \& Schmidt, 2003; Podsakoff, MacKenzie, \& Bommer, 1996; Stewart \& Roth, 2001) pose the risk of undue generalization over time.

${ }^{3}$ Cohen, 1991 speaks about the 'natural history' of a phenomenon and mentions such aspects as: onset, growth, recovery, persistence and decline, which are covered by our characterization of temporality.

${ }^{4}$ This is also true at a micro level as is obvious from early time-and-motion studies (e.g. Gilbreth \& Gilbreth, 1917) in which optimal muscular movements were identified.

${ }^{5}$ For any given phenomenon there may be one or more other phenomena that are influenced by the same antecedent phenomenon and have an effect on the same consequent phenomenon. For this reason is it commendable to define and study concomitant phenomena. For reasons of simplicity the notion of concomitant phenomenon is not used in this article.

${ }^{6}$ The five models are labeled: Stress reaction mode, Accumulation model, Dynamic accumulation model, Adjustment model, Sleeper effect model

${ }^{7}$ The same is true for the relationships between antecedent and concomitant, focal and concomitant, and concomitant and consequent phenomena. Although this may be interesting when aiming for the development of more integrated theories of $\mathrm{OB}$, we leave these applications out of account.

${ }^{8}$ This touches upon an intriguing issue, i.e. that of the stability of temporal patterns over time, which we will discuss under the heading of temporal conditioning.

${ }^{9}$ Research according to this paradigm may also focus on concomitant phenomena. This would open the way to the study of broader patterns of OB, e.g. comprising multiple attitudes, such as job satisfaction, organizational commitment and job involvement. This might help to achieve a deeper understanding of $\mathrm{OB}$ in the long run and 
provides answers to questions from organizational practice about how the overall picture of employee attitudes is, and how employees' overall response to certain organizational changes is.

${ }^{10}$ Relative time can also be referred to a clock time, since the measurement ignores exact dates. Absolute time can be referred to as calendar time, since exact dates do matter. Philosophically speaking all times are relative times, since even calendars have an arbitrary origin. Hence, we also speak of quasi -absolute time.

${ }^{11} \mathrm{Cf}$ the assumption of stationarity in time-series analysis

${ }^{12}$ We confine ourselves to the measurement of objective time. Measuring subjective time is another issue which poses its own (Zakay, 1990).

${ }^{13}$ According to Cliff (1991) non-parametric analysis of ordinal data are quite appropriate for many purposes. After all, he notes, many parametric analyses of interval data are interpreted in ordinal terms ("takes longer than ...", “develops more slowly than ...") anyway.

${ }^{14}$ Causal analysis requires: reliable covariation, temporal order, and controlled manipulation to rule out a $3^{\text {rd }}$ cause. Note that here variables here refer to specific temporal parameters of the phenomena. 


\section{References}

Aldefer, C. P. (1972). Existence, relatedness and growth: Human needs in organizational settings. New York: Free Press.

Allison, P. D. (1984). Event history analysis: Regression for longitudinal event data. Beverly Hills, CA: Sage.

Alluisi, E. A., \& Morgan, B. B. (1982). Temporal factors in human performance and productivity. In E. A. Alluisi \& E. A. Fleishman (Eds.), Stress and performance effectiveness (pp. 165-247). Hillsdale NJ: Lawrence Erlbaum.

Ancona, D. G., \& Chong, C. L. (1999). Cycles and synchrony: The temporal role of context in team behavior. In R. Wageman (Ed.), Research on managing groups and teams: Groups in context, Vol. 2 (pp. 33-48). Stamford, CT: JAI Press, Inc.

Ancona, D. G., Goodman, P. S., Lawrence, B. S., \& Tushman, M. L. (2001). Time: a new research lens. Academy of Management Review, 26, 645-663.

Aryee, S., Budhwar, P. S., \& Chen, Z. X. (2002). Trust as a mediator of the relationship between organizational justice and work outcomes: Test of a social exchange model. Journal of Organizational Behavior, 23(3), 267-286.

Axinn, W. G., Pearce, L. D., \& Ghimire, D. (1999). Innovations in life history calendar applications. Social Science Research, 28(3), 243-264.

Baron, R. M., \& Kenny, D. A. (1986). The moderator-mediator variable distinction in social psychological research: conceptual, strategic, and statistical considerations. Journal of Personality and Social Psychology, 51, 1173-1182.

Beard, J. W., Woodman, R. W., \& Moesel, D. (1998). Using behavioral modification to change attendance patterns in the high-performance, high-commitment environment. In W. A. Pasmore \& R. W. Woodman (Eds.), Research in organizational change and development. An annual series featuring advances in theory, methodology, and research (Vol. 11, pp. 183-224): Elsevier Science/JAI Press.

Beck, K., \& Wilson, C. (2000). Development of affective organizational commitment: A crosssequential examination of change with tenure. Journal of Vocational Behavior, 56(1), $114-136$.

Bergh, D. D. (1993). Watch the time carefully: the use and misue of time effects in management research. Journal of Management, 19(3), 683-705.

Bergman, M. E., Langhout, R. D., Palmieri, P. A., Cortina, L. M., \& Fitzgerald, L. F. (2002). The (un)reasonableness of reporting: Antecedents and consequences of reporting sexual harassment. Journal of Applied Psychology, 87(2), 230-242.

Bernhardt, K. L., Donthu, N., \& Kennett, P. A. (2000). A longitudinal analysis of satisfaction and profitability. Journal of Business Research, 47(2), 161-171.

Biesanz, J. C., Deeb-Sossa, N., Papadakis, A. A., Bollen, K. A., \& Curran, P. J. (2004). The role of coding time in estimating and interpreting growth curve models. Psychological Methods, 9(1), 30-52.

Bluedorn, A. C. (2002). The human organization of time. Temporal realities and experience. Stanford, CA: Stanford University Press.

Bluedorn, A. C., \& Denhardt, R. C. (1988). Time and organizations. Journal of Management, 14(2), 299-320.

Boeker, W., \& Karichalil, R. (2002). Entrepreneurial transitions: Factors influencing founder departure. Academy of Management Journal, 45(4), 818-826. 
Bolger, N., Davis, A., \& Rafaeli, E. (2003). Diary methods: Capturing life as it is lived. Annual Review of Psychology, 54, 579-616.

Box, G. E. P., Jenkins, G. M., \& Reinsel, G. C. (1994). Time series analysis: Forecasting and control. Englewood Cliffs, NJ: Prentice Hall.

Bryck, A. S., \& Raudenbusch, S. W. (1987). Application of hierarchical linear models ro assessing change. Psychological Bulletin, 101, 147-158.

Bryck, A. S., \& Raudenbusch, S. W. (1992). Hierachical linear models. Thousand Oaks, CA: Sage.

Burchinal, M., \& Appelbaum, M. I. (1991). Estimating individual developmental functions: Methods and their assumptions. Child Development, 62(1), 23-43.

Buss, A. R. (1979). Toward a unfiied framework for psychometric concepts in the multivariate development situation: Intraindividual change and inter- and intraindividual differences. In J. R. Nesselroade \& P. B. Baltes (Eds.), Longitudinal research in the study of behavior and development (pp. 41-59). New York: Academic Press.

Chan, D. (1998). The conceptualization and analysis of change over time: An interactive approach incorporating longitudinal mean and covariance structure analysis (LMACS) and multiple indicator latent growth modeling (MLGM). Organizational Research Methods, 1(4), 421-483.

Chan, D. (2002). Latent growth modeling. In F. Drasgow \& N. Schmitt (Eds.), Measuring and analyzing behavior in organizations: Advances in measurement and data analysis (pp. 302-349). San Francisco, CA: Jossey-Bass.

Chan, D., Ramey, S., ., Ramey, C., \& Schmitt, N. (2000). Modeling intraindividual changes in children's social skills at home and at school: A multivariate latent growth approach to understanding between-settings differences in children's social skill development. Multivariate Behavioral Research, 35(3), 365-396.

Chisletta, P., \& McArdle, J. J. (2001). Latent growth curve analyses of the development of height. Structural Equation Modeling, 8(4), 531-555.

Claessens, B. (2004). Time management. (PhD Thesis). Eindhoven: Eindhoven University of Technology.

Cohen, A. (2003). Multiple commitments in the workplace: An integrative approach., Series in Applied Psychology. Mahwah, NJ: Lawrence Erlbaum.

Cohen, A. A., \& Lemish, D. (2003). Real time and recall measures of mobile phone use: Some methodological concerns and empirical applications. New Media and Society, 5(2), 167183.

Cohen, P. (1991). A source of bias in longitudinal investigations of change. In 1. M. Collins \& J. L. Horn (Eds.), Best methods for the analysis of change (pp. 18-25). Washington, DC: American Psychological Association.

Collins, L. M. (1991). Measurement in longitudinal research. In J. L. Horn (Ed.), Best methods for the analysis of change: recent advances, unanswered questions, future directions (pp. 137-148). Washington, DC: American Psychological Association.

Collins, L. M., \& Graham, J. W. (1991). Comments on 'A source of bias in logitudinal investigations of change' by P. Cohen. In J. L. Horn (Ed.), Best methods for the analysis of change (pp. 26-30). Washington, D.C.: American Psychological Association.

Cox, D. R. (1972). Regression models and life tables. Journal of the Royal Statistical Society, Series B, 34, 187-120. 
Csikszentmihalyi, M., \& Hunter, J. (2003). Happiness in everyday life: The uses of experience sampling. Journal of Happiness Studies, 4(2), 185-199.

Cunningham, W. R. (1991). Issues in factorial invariance. In L. M. Collins \& J. L. Horn (Eds.), Best methods for the analysis of change: recent advances, unanswered questions, future directions (pp. 106-113). Washington, DC: American Psychological Association.

Curran, P. J., Bauer, D. J., \& Willoughby, M. T. (2004). Testing main effects and interactions in latent curve analysis. Psychological Methods, 9(2), 220-237.

Davey, A., Shanahan, M. J., \& Schafer, J. L. (2001). Correcting for selective non-response in the National Longitudinal Survey of Youth using multiple imputation. Journal of Human Resources, 36(3), 500-519.

Dekimpe, M. G., \& Hanssens, D. M. (2000). Time-series models in marketing: past, present and future. International Journal of Research in Marketing, 17, 183-193.

Denison, D. (Ed.). (2001). Organizational change in transition economies. London: Sage.

Dershimer, R. A., \& Conover, S. (1989). The stimulated recall technique: A qualitative evaluation of an in-service workshop. Hospice Journal, 5(2), 85-93.

Dickter, D. N., Roznowski, M., \& Harrison, D. A. (1996). Temporal tempering: An event history analysis of the process of voluntary turnover. Journal of Applied Psychology, 81(6), 705716.

Edwards, J. R. (1994). Regression analysis as an alternative to difference scores. Journal of Management, 29, 683-689.

Ettlie, J. E. (1977). Real-time studies in organizational research. Academy of Management Review, 298-302.

Flynn, D. M., \& Tannenbaum, S. I. (1993). Correlates of organizational commitment: Differences in the public and private sector. Journal of Business and Psychology, 8, 103116.

Francis-Smythe, J., \& Robertson, I. (1999). Time-related individual differences. Time \& Society, $8(2), 273-292$.

Freedman, D., Thornton, A., Cadburn, D., Alwin, D., \& Young-DeMarco, L. (1988). The lifehistory calendar: A technique for collecting retrospective data. Sociological Methodology, 18, 37-68.

Frese, M., \& Zapf, D. (1988). Methodological issues in the study of work stress: Objective vs subjective measurement of work stress and the question of longitudinal studies. In C. L. Cooper \& R. Payne (Eds.), Causes, coping and consequences of stress at work (pp. 375411). Chichester: John Wiley \& Sons.

Fried, Y., \& Slowik, L. H. (2004). Enriching Goal-Setting Theory with Time: An Integrated Approach. Academy of Management Review, 29(3), 404-422.

Fuller, J. A., Stanton, J. M., Fisher, G. G., Spitzmuller, C., Russell, S. S., \& Smith, P. C. (2003). A Lengthy Look at the Daily Grind: Time Series Analysis of Events, Mood, Stress, and Satisfaction. Journal of Applied Psychology, 88(6), 1019-1033.

George, J. M., \& Jones, G. R. (2000). The role of time in theory and theory building. Journal of Management, 26, 657-684.

Gevers, J. M. P. (2004). It's about time we align: Meeting deadlines in project teams. (PhD Thesis). Eindhoven: Eindhoven University of Technology.

Gevers, J. M. P., Rutte, C. G., \& Van Eerde, W. (2004). Meeting deadlines in work groups: The role of shared temporal cognitions. Paper presented at SIOP conference, Chicago, USA.

Gilbreth, F., \& Gilbreth, L. (1917). Applied Motion Study. New York: Sturgis \& Walton Co. 
Glenn, N. D. (1977). Cohort analysis (Vol. 07-005). Londeon: Sage Publications.

Grondin, S. (2001). From physical time to the first and second moments of psychological time. Psychological Bulletin, 127(1), 22-44.

Guastello, S. J. (1995). Chaos, catastrophe, and human affairs. Applications of nonlinear dynamics to work, organizations, and social evolution. Mahwah, NJ: Lawrence Erlbaum Associates.

Hambrick, D. C., Cho, T. C., \& Chen, M. J. (1996). The influence of top management team heterogeneity on firms' competitive moves. Administrative Science Quarterly, 41, 659684.

Heller, D., Judge, T. A., \& Watson, D. (2002). The confounding role of personality and trait affectivity in the relationship between job and life satisfaction. Journal of Organizational Behavior, 23(7), 815-835.

Henry, R. A., \& Hulin, C. L. (1987). Stability of skilled performance across time: Some generalizations and limitations on utilities. Journal of Applied Psychology, 72(3), 457462.

Hofmann, D. A. (1997). An overview of the logic and rationale of hierarchical linear models. Journal of Management, 23, 723-744.

Hofmann, D. A., Jacobs, R., \& Baratta, J. E. (1993). Dynamic criteria and the measurement of change. Journal of Applied Psychology, 78(2), 194-204.

Hofstede, G. (2001). Culture's consequences: Comparing values, behaviors, institutions, and organizations across nations. London: Sage.

Holton, E. F., \& Russell, C. J. (1999). Organizatinal entry and exit: An exploratory longitudinal examination of early careers. Human Performance, 12(3-4), 311-341.

Hom, P. W., \& Kinicki, A. J. (2001). Toward a greater understanding of how dissatisfaction drives employee turnover. Academy of Management Journal, 44(5), 975-987.

Ilgen, D. R., \& Hulin, C. L. (Eds.). (2000). Computational modeling of behavior in organizations. The third scientific discipline. Wahsington, DC: American Psychological Association.

Iverson, R. D., \& Pullman, J. A. (2000). Determinants of voluntary turnover and layoffs in an environment of repeated downsizing following a merger: An event history analysis. Journal of Management, 26(5), 977-1003.

Jaros, S. J. (1997). An assessment of Meyer and Allen's (1991) three-component model of organizational commitment and turnover intentions. Journal of Vocational Behavior, 51, 319-337.

Jones, F., \& Fletcher, B. (1996). Taking work home: A study of daily fluctuations in work stressors, effects on moods and impacts on marital partners. Journal of Occupational and Organizational Psychology, 69(1), 89-106.

Judge, T. A., \& Watanabe, S. (1995). Is the past prologue? A test of Ghiselli's hobo syndrome. Journal of Management, 21(2), 211-229.

Kammeyer Mueller, J. D., \& Wanberg, C. R. (2003). Unwrapping the organizational entry process: Disentangling multiple antecedents and their pathways to adjustment. Journal of Applied Psychology, 88(5), 779-794.

Kaufman-Scarborough, C., \& Lindquist, J. D. (1999). Time management and polychronicity. Journal of Managerial Psychology, 14(3/4), 288-312.

Kiefer, N. M. (1988). Economic duration data and hazard functions. Journal of Economic Literature, 26(June), 646-679. 
Ko, J.-W., Price, J. L., \& Mueller, C. W. (1997). Assessment of Meyer and Allen's ThreeComponent Model of Organizational Commitment in South Korea., Journal of Applied Psychology (Vol. 82, pp. 961-973): American Psychological Association.

Koenigsberg, J., Garet, M. S., \& Rosenbaum, J. E. (1994). The effect of family on the job exits of young adults: A competing risk model. Work and Occupations, 21(1), 33-63.

Laird, N. M., \& Ware, J. H. (1982). Random-effect models for longitudinal data. Biometrika, 39, 963-974.

Lance, C. E., \& Vandenberg, R. J. (2000). Latent growth models of newcomer change: The case of newcomer adjustment. Organizational Behavior and Human Decision Processes, 83(1), 107-140.

Lee, H. (2003). Your time and my time: A temporal apporach to groupware calendar systems. Information \& Management, 40, 159-164.

Luke, D. A. (1993). Charting the process of change: A primer on survival analysis. American Journal of Community Psychology, 21(2), 203-246.

Luna, T. D., French, J., \& Mitcha, J. L. (1997). A study of USAF air traffic controller shiftwork: Sleep, fatigue, activity, and mood analyses. Aviation, Space, and Environmental Medicine, 68(1), 18-23.

Macan, T. H. (1994). Time management: Test of a process model. Journal of Applied Psychology, 79(3), 381-391.

Manz, C. C., \& Sims, H. P. (1993). Business without bosses. How self-managing teams are building high-performing companies. New York: John Wiley \& Sons.

Maslow, A. H. (1954). Motivation and personality. New York: Harper \& Row.

McArdle, J. J. (2001). Growth curve analysis. In International Encyclopedia of the Social Sciences (pp. 6439-6445): Elsevier Science Ltd.

McGrath, J. E., \& Kelly, J. R. (1986). Time and human interaction: Toward a social psychology of time. New York, NY, US: Guilford Press.

McGrath, J. E., \& Tschan, F. (2004). Temporal matters in social psychology. Washington, DC: American Psychological Association.

Meloen, J. D. (1983). The authoritarian reaction in times of welfare and crisis [Dutch: De autoritaire reactie in tijden van welvaart en krisis]. Amsterdam: PhD Thesis University of Amsterdam.

Menard, S. (1991). Longitudinal research (Vol. 07-076). Newbury Park, CA: Sage.

Meredith, W., \& Tisak, J. (1990). Latent curve analysis. Psychometrika, 55, 107-122.

Meyer, J. P., \& Allen, N. J. (1991). A three-component conceptualization of organizational commitment. Human Resource Management Review, 1, 61-89.

Meyer, J. P., Bobocel, D. R., \& Allen, N. J. (1991). Development of organizational commitment during the first year of employment: A longitudinal study of pre- and post-entry influences. Journal of Management, 17, 717-733.

Miners, I. A., Moore, M. L., Champoux, J. E., \& Martocchio, J. J. (1994). Organization Development Impacts Interrupted: A Multiyear Time-serial Study of Absence and Other Time Uses. Group \& Organization Management, 19(3), 363-394.

Mitchell, T. R., \& James, L. R. (2001). Building better theory: Time and the specification of when things happen. Academy of Management Review, 26(4), 530-547.

Nesselroade, J. R., \& Baltes, P. B. (1979). Longitudinal researcg in the study of behavior and development. London: Academic Press. 
Ones, D. S., Viswesvaran, C., \& Schmidt, F. L. (2003). Personality and absenteeism: A metaanalysis of integrity tests. European Journal of Personality, 17(Suppl1), S19-S38.

Ostrom, C. W. (1978). Time series analysis: regression techniques (Vol. 07-009). London: Sage.

Palmer, D. K., \& Schoorman, F. D. (1999). Unpackaging the multiple aspects of time in prolychronicity. Journal of Managerial Psychology, 14(3/4), 323-344.

Parmar, M. K. B., \& Machin, D. (1995). Survival analysis: A practical approach. Chichester: John Wiley \& Sons.

Pearce, J. L., Stevenson, W. B., \& Perry, J. L. (1985a). Managerial compensation based on organizational performance: A time series analysis of the effects of merit pay. Academy of Management Journal, 28, 261-278.

Pearce, J. L., Stevenson, W. B., \& Perry, J. L. (1985b). Managerial compensation based on organizational performance: A time series analysis of the effects of merit pay. Academy of Management Journal, 28(2), 261-278.

Pena, D., \& Tiao, G. C. (2001). Introduction. In D. Pena, G. C. Tiao \& R. S. Tsay (Eds.), $A$ course in time series analysis (Vol. John Wiley \& Sons, pp. 1-21). New York.

Pettigrew, A. M. (1990). Longitudinal field research on change: theory and practice. Organization Science, 1(3), 267-292.

Ployhart, R. E., Holtz, B. C., \& Bliese, P. D. (2002). Longitudinal data analysis applications of random coefficient modeling to leadership research. Leadership Quarterly, 13(4), 455486.

Podsakoff, P. M., MacKenzie, S. B., \& Bommer, W. H. (1996). Meta-analysis of the relationships between Kerr and Jermier's substitutes for leadership and employee job attitudes, role perceptions, and performance. Journal of Applied Psychology, 81(4), 380399.

Pritchard, R. D., Jones, S. D., Roth, P. L., Stuebing, K. K., \& et al. (1988). Effects of group feedback, goal setting, and incentives on organizational productivity.

Rastegary, H., \& Landy, F. J. (1993). The interactions among time urgency, uncertainty, and time pressure. In O. Svenson \& A. J. Maulel (Eds.), Time pressure and stress in human judgement and decision making (pp. 217-239). New York: Plenum Press.

Reddy, R., Rhodes, J. E., \& Mulhall, P. (2003). The influence of teacher support on student adjustment in the middle school years. A latent growth curve study. Development and Psychopathology, 15, 119-138.

Robinson, S. L., \& Morrison, E. W. (2000). The development of psychological contract breach and violation: A longitudinal study. Journal of Organizational Behavior, 21(5), 525-546.

Roe, R. A. (2004). De paradox van de tijd en de toekomst van A\&O psychologisch onderzoek [The paradox of time and the future of research in W\&O psychology]. Gedrag \& Organisatie, 17(5), 342-350.

Roe, R. A., \& Quist, S. J. (2004). Strengths and limitations of work calendars as a research tool.Unpublished manuscript, Maastricht: Universiteit Maastricht, Faculty of Economics \& Business Administration.

Roe, R. A., Zinovieva, I. L., Dienes, E., \& Ten Horn, L. A. (2000). A comparison of work motivation in Bulgaria, Hungary, and the Netherlands: Test of a model. Applied Psychology: An International Review, 49(4), 658-687.

Roeckelein, J. E. (2000). The concept of time in psychology. A resource book and annotated bibligraphy. Westport, $\mathrm{Ct}$

London: Greenwood Press. 
Rogosa, D. R. (1995). Myths and methods: "myths about longitudinal research" plus supplemental questions. In J. M. Gottman (Ed.), The analysis of change (pp. 3-66). Mahwah, NJ: Lawrence Erlbaum Associates.

Rogosa, D. R., \& Willett, J. B. (1983). Demonstrating the reliability of the difference score in the measurement of change. Journal of Educational Measurement, 20(4), 335-343.

Rousseau, D. M., \& Fried, Y. (2001). Location, location, location. Contextualizing organizational research. Journal of Organizational Behavior, 22, 1-13.

Rousseau, D. M., \& Wade Benzoni, K. A. (1995). Changing individual-organization attachments: A two-way street. In A. Howard (Ed.), The changing nature of work (pp. 290-322). Publishers, San Francisco, CA: Jossey-Bass Inc.

Rudinger, G., \& Rietz, C. (1998). The neglected time dimension? Introducing a longitudinal model testing latent growth curves, stability, and reliability as time bound processes. Methods of Psychological Research Online, 3(2), 109-130.

Russell, C. J. (2001). A longitudinal study of top-level executive performance. Journal of Applied Psychology, 86(4), 560-573.

Sawyer, J. E., Latham, W. R., Pritchard, R. D., \& Bennett, W. R., Jr. (1999). Analysis of work group productivity in an applied setting: Application of a time series panel design. Personnel Psychology, 52(4), 927-967.

Schein, E. (1985). Organizational culture and leadership. San Francisco: Jossey-Bass.

Seeley, M., \& Targett, D. (1999). Patterns of senior executives' personal use of computers. Information \& Management, 35, 315-330.

Seers, A., \& Woodruff, S. (1997). Temporal pacing in task forces: Group development or deadline pressure? Journal of Management, 23, 169-187.

Slife, B. D. (1993). Time and psychological explanation. Albany, NY: State University of New York Press.

Slocombe, T. E. (1999). Applying the theoryu of reasoned action to the analysis of an individual's polychronicity. Journal of Managerial Psychology, 14(3/4), 313-322.

Smith, B. D., \& Tonidandel, S. (2003). Taking account of time: the application of event history analysis to leadership research. Leadership Quarterly, 14, 241-256.

Somers, M. J., \& Birnbaum, D. (1999). Survival versus traditional methodologies for studying employee turnover: Differences, divergences and directions for future research. Journal of Organizational Behavior, 20(2), 273-284.

Stewart, W. H., Jr., \& Roth, P. L. (2001). Risk propensity differences between entrepreneurs and managers: A meta-analytic review. Journal of Applied Psychology, 86(1), 145-153.

Stockton, R., Morran, D., \& Clark, M. B. (2004). An Investigation of Group Leaders' Intentions. Group Dynamics, 8(3), 196-206.

Stoel, R. D., Peetsma, T. T. D., \& Roeleveld, J. (2003). Relations between the development of school investment, self-confidence, and language achievementin elementary education: A multivariate latent growth curve apporach. Learning and Individual Differences, 13, 313333.

Stoolmiller, M. (1995). Using latent growth curve models to study developmental processes. In J. M. Gottmann (Ed.), The analysis of change (pp. 103-139). Hillsdale, NJ: Lawrence Erlbaum.

Tisak, J., \& Smith, C. S. (1994). Defending and extending difference score methods. Journal of Management, 29(675-682). 
Totterdell, P., Spelten, E., Smith, L., Barton, J., \& et al. (1995). Recovery from work shifts: How long does it take? Journal of Applied Psychology, 80(1), 43-57.

Trevor, C. O. (2001). Interactions among actual ease-of-movement determinants and job satisfaction in the prediction of voluntary turnover. Academy of Management Journal, 44(4), 621-638.

Van Wijk, J. J., \& Selow, E. R. v. (1999). Cluster and calendar-based visualization of time series data. In G. Wills \& D. Keim (Eds.), IEEE Symposium on Information Visualization (pp. 4-9). San Francisco, Cal: IEEE Computer Society.

Wagner, J. A., Rubin, P. A., \& Callahan, T. J. (1988). Incentive payment and nonmanagerial productivity: An interrupted time series analysis of magnitude and trend. Organizational Behavior and Human Decision Processes, 42(1), 47-74.

Walker, K. D. (1999). A survival analysis approach to employee turnover: Its application and advantages. Dissertation Abstracts International: Section B: The Sciences and Engineering, 59(7-B), 3750.

Waller, M. J. (1995). Multitasking in work groups: Coordination processes in work groups with multiple tasks. Dissertation Abstracts International Section A: Humanities and Social Sciences, 56(6-A), 2328.

Waller, M. J., Conte, J. M., Gibson, C. B., \& Carpenter, M. A. (2001). The effect of individual perceptions of deadlines on team performance. Academy of Management Review, 26(4), 586-600.

Waller, M. J., Zellmer Bruhn, M. E., \& Giambatista, R. C. (2002). Watching the clock: Group pacing behavior under dynamic deadlines. Academy of Management Journal, 45(5), 1046-1055.

Werts, C. E., \& Linn, R. L. (1970). A general linear model for studying growth. Psychological Bulletin, 73, 17-22.

Willett, J. B., \& Sayer, A. G. (1994). Using covariance structure analysis to detect correlates and predictors of individual change over time. Psychological Bulletin, 116, 363-381.

Witt, L. A., Kacmar, K. M., \& Andrews, M. C. (2001). The interactive effects of procedural justice and exchange ideology on supervisor-rated commitment. Journal of Organizational Behavior, 22(5), 505-515.

Wohlwill, J. F. (1973). The study of behavioral development. New York: Academic Press.

Wright, R. E. (2000). Survival analysis. In L. Grimm \& P. Yarnold (Eds.), Reading and understanding more multivariate statistics (pp. 363-408). Washington DC: American Psychological Association.

Yamaguchi, S. (1991). Event history analysis. Newbury Park, CA: Sage.

Zakay, D. (1990). The evasive art of subjective time measurement: Some methodologival dillemmas. In R. A. Block (Ed.), Cognitive model of psychological time (pp. 59-84). Hillsdale, NJ: Lawrence Erlbaum Associates.

Zimbardo, P. G., \& Boyd, J. N. (1999). Putting time in perspective; A valid, reliable individual difference metric. Journal of Personality and Social Psychology, 77(6), 1271-1288. 


\section{Author Note}

The author acknowledges the help of Michael Fokkens in gathering the literature used in this article, and of Woody van Olffen, Anneloes Raes and Omar Solinger in providing comments on an earlier version of the manuscript. 
Table 1

Scheme for the temporal analysis of pairs of phenomena

\begin{tabular}{|l|l|c|c|c|}
\hline \multicolumn{1}{|c|}{} & \multicolumn{3}{|c|}{ Phenomenon P } \\
\cline { 2 - 5 } & Char & Onset & Duration & Dynamics \\
\hline \multirow{3}{*}{ Phenomenon Q } & Onset & 1 & 4 & 7 \\
\cline { 2 - 5 } & Duration & 2 & 5 & 8 \\
\cline { 2 - 5 } & Dynamics & 3 & 6 & 9 \\
\hline
\end{tabular}


Table 2

Methods of analysis in temporal research

\begin{tabular}{|c|c|c|c|}
\hline Research aims & $\begin{array}{c}\text { I. Temporal } \\
\text { modeling }\end{array}$ & $\begin{array}{c}\text { II. Analysis of } \\
\text { temporal } \\
\text { relationships }\end{array}$ & $\begin{array}{c}\text { III. Assessment of } \\
\text { long-term } \\
\text { constancy }\end{array}$ \\
\hline $\begin{array}{c}\text { Descriptive } \\
\text { modeling }\end{array}$ & $\mathrm{X}$ & & \\
\hline $\begin{array}{c}\text { Random } \\
\text { Coefficient } \\
\text { Modeling }\end{array}$ & $\mathrm{X}$ & $\mathrm{X}$ & \\
\hline $\begin{array}{c}\text { Latent Growth } \\
\text { Modeling }\end{array}$ & $\mathrm{X}$ & $\mathrm{X}$ & \\
\hline $\begin{array}{c}\text { Event History } \\
\text { Analysis }\end{array}$ & $\mathrm{X}$ & $\mathrm{X}$ & $\mathrm{X}$ \\
\hline $\begin{array}{c}\text { Time Series } \\
\text { Analysis }\end{array}$ & $\mathrm{X}$ & $\mathrm{X}$ & $\mathrm{X}$ \\
\hline $\begin{array}{c}\text { Analysis of } \\
\text { Variance }\end{array}$ & $(\mathrm{X})$ & $\mathrm{X}$ & $\mathrm{X}$ \\
\hline $\begin{array}{c}\text { Regression } \\
\text { Analysis }\end{array}$ & $(\mathrm{X})$ & & \\
\hline
\end{tabular}


Table 3

Time scales and resolution

Quasi / absolute time (calendar time)

\begin{tabular}{|c|c|c|c|c|c|c|c|}
\hline \multirow{4}{*}{ 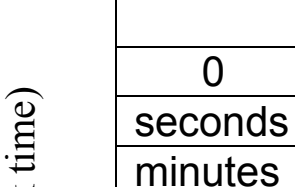 } & 0 & weeks & months & quarters & years & decades & centuries \\
\hline & & & & & & & \\
\hline & & & & & & & \\
\hline & & & & & & & \\
\hline hours & & & & & & & \\
\hline days & & & & & & & \\
\hline weeks & & & & & & & \\
\hline months & & & & & & & \\
\hline quarters & & & & & & & \\
\hline years & & & & & & & \\
\hline decades & & & & & & & \\
\hline
\end{tabular}


Figure Captions

Figure 1: Generic model of temporality of phenomena

Figure 2: Different types of dynamics of phenomena

Figure 3: Recurrent regular and irregular

Figure 4: Hierarchical representation of recurrent phenomena

Figure 5: Models of variables and phenomena compared

Figure 6: Basic latent growth model (with correlated error terms)

Figure 7: Two hazard functions for attendees and nonattendees of a leadership development program (Smith \& Tonidandel, 2003) 
Figure 1: Generic model of temporality of phenomena

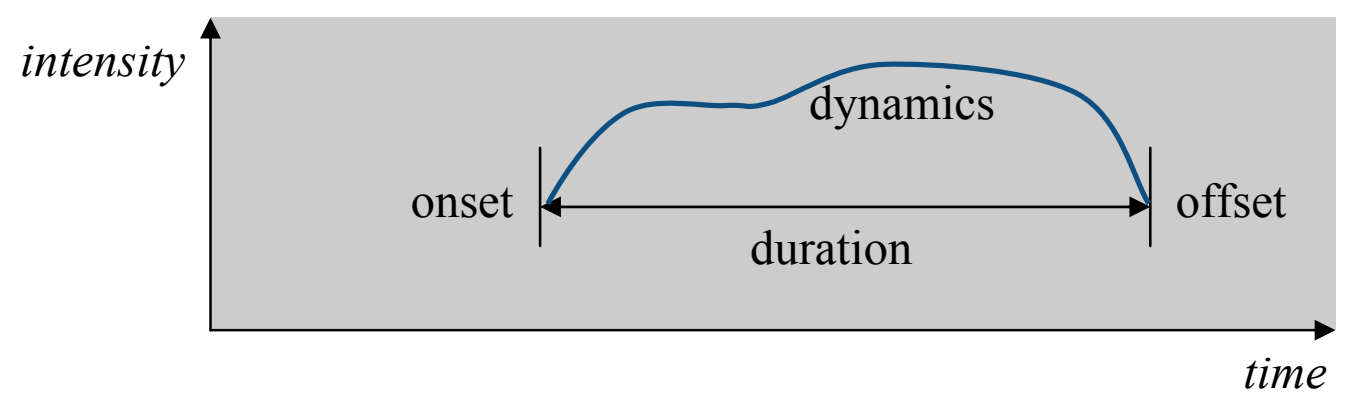


Figure 2: Different types of dynamics of phenomena
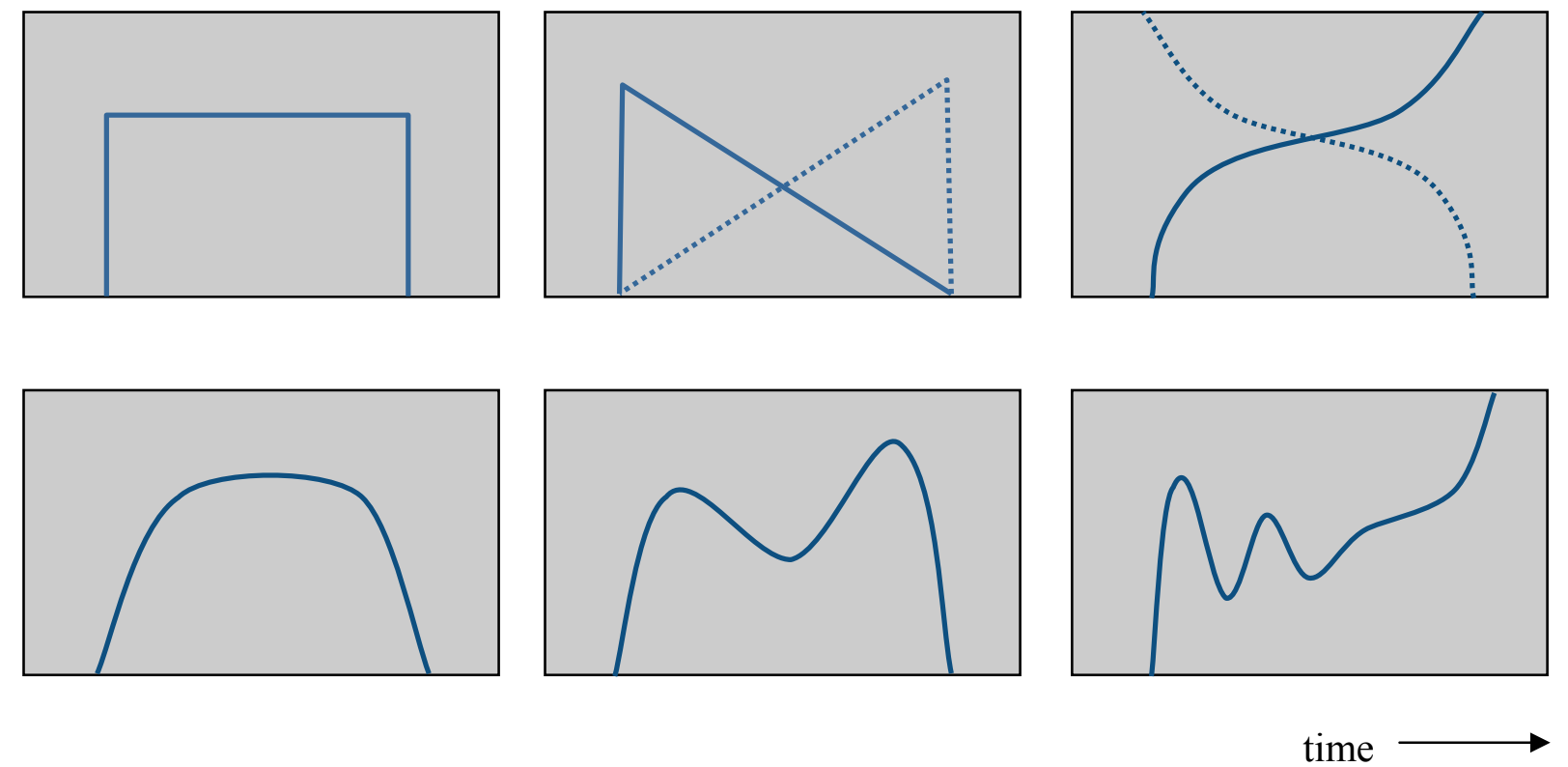
Figure 3: Recurrent regular and irregular
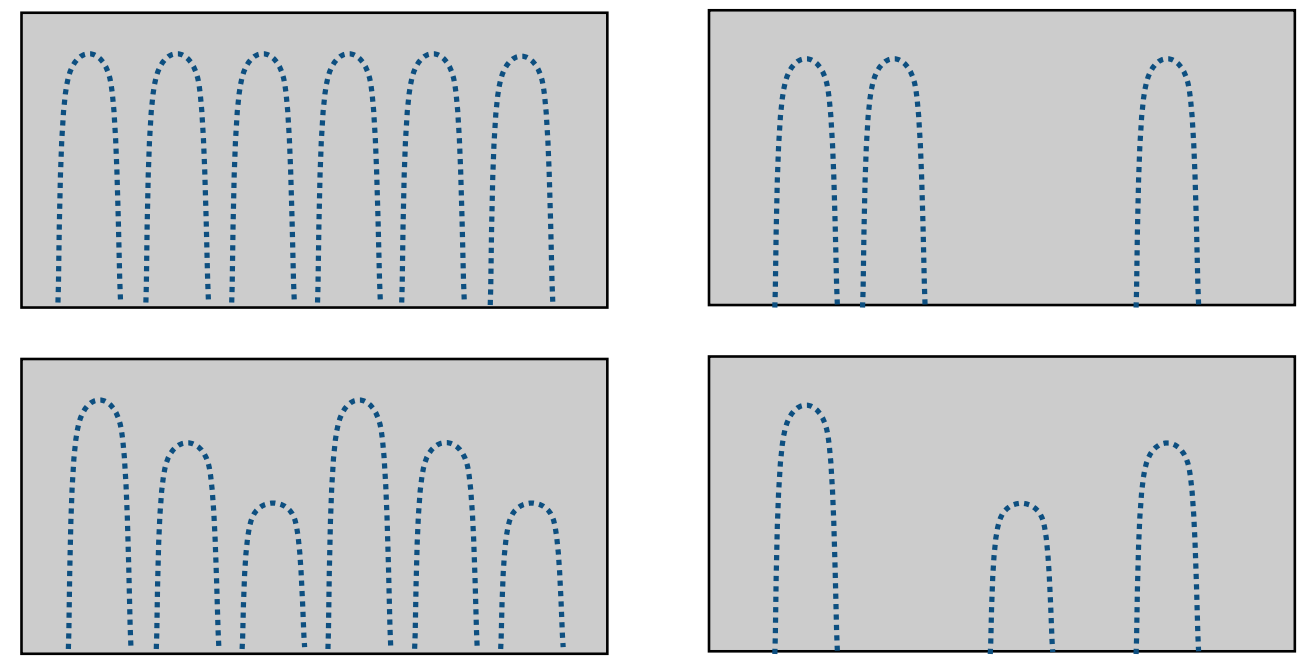

time 
Figure 4: Hierarchical representation of recurrent phenomena

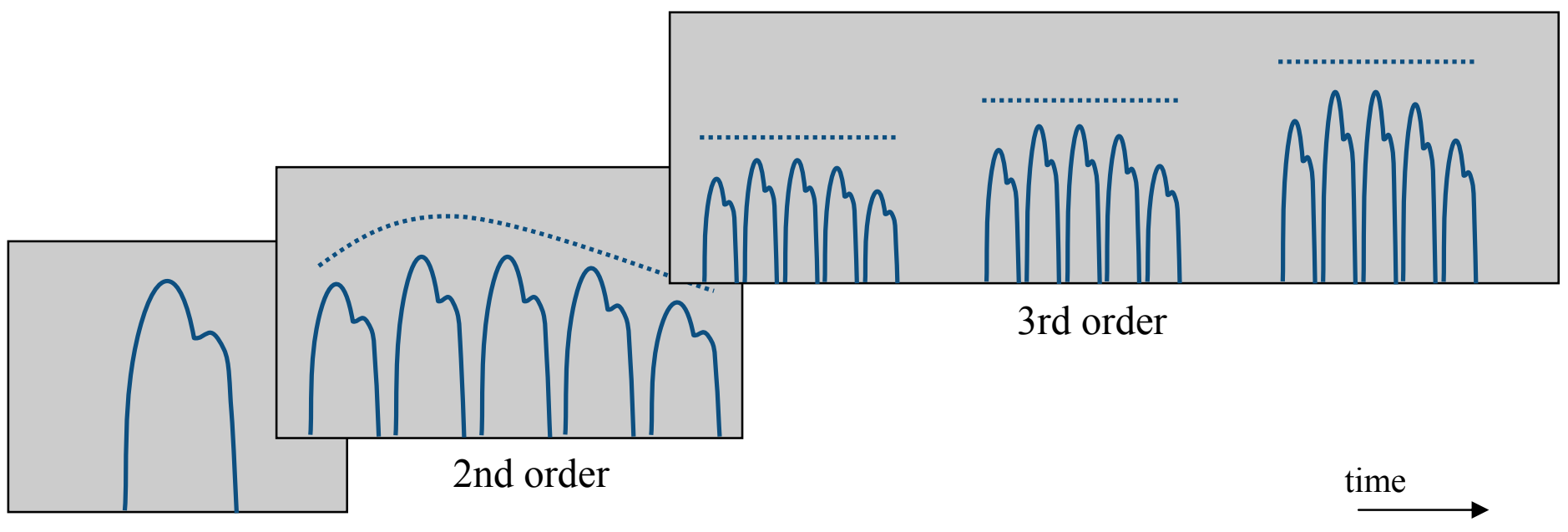

1 st order 
Figure 5: Models of variables and phenomena compared
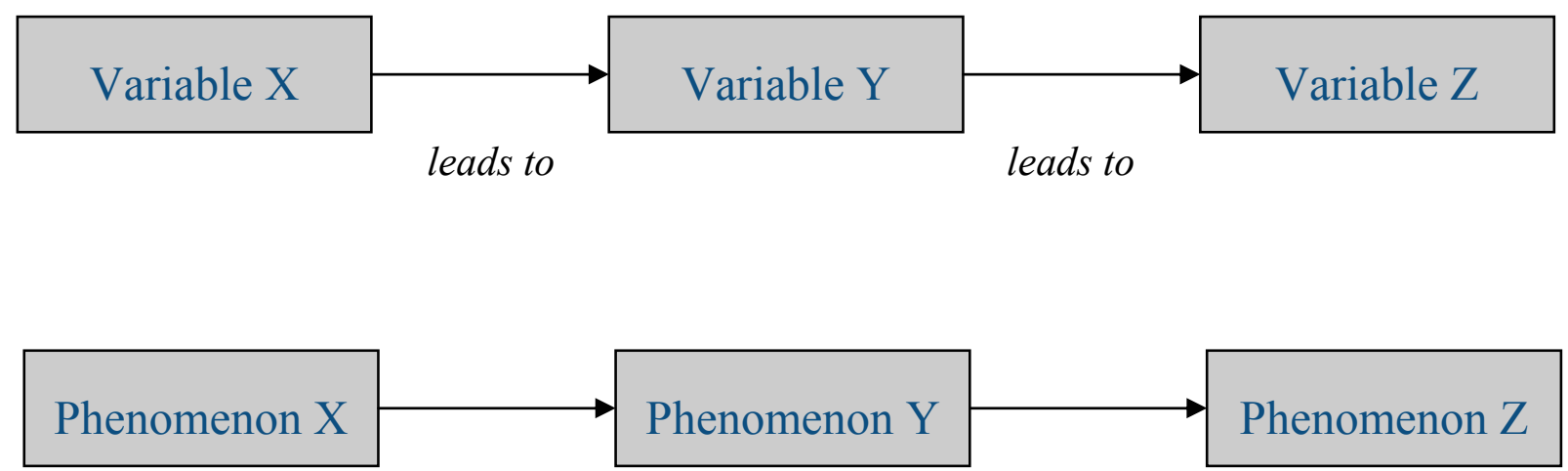

after a certain exposure to a particular pattern of $X$, and after a given delay, there will be a change in $Y$ if $Y$ has changed durably, there will after some time be a certain type of change in $Z$ 
Figure 6: Basic latent growth model (with correlated error terms)

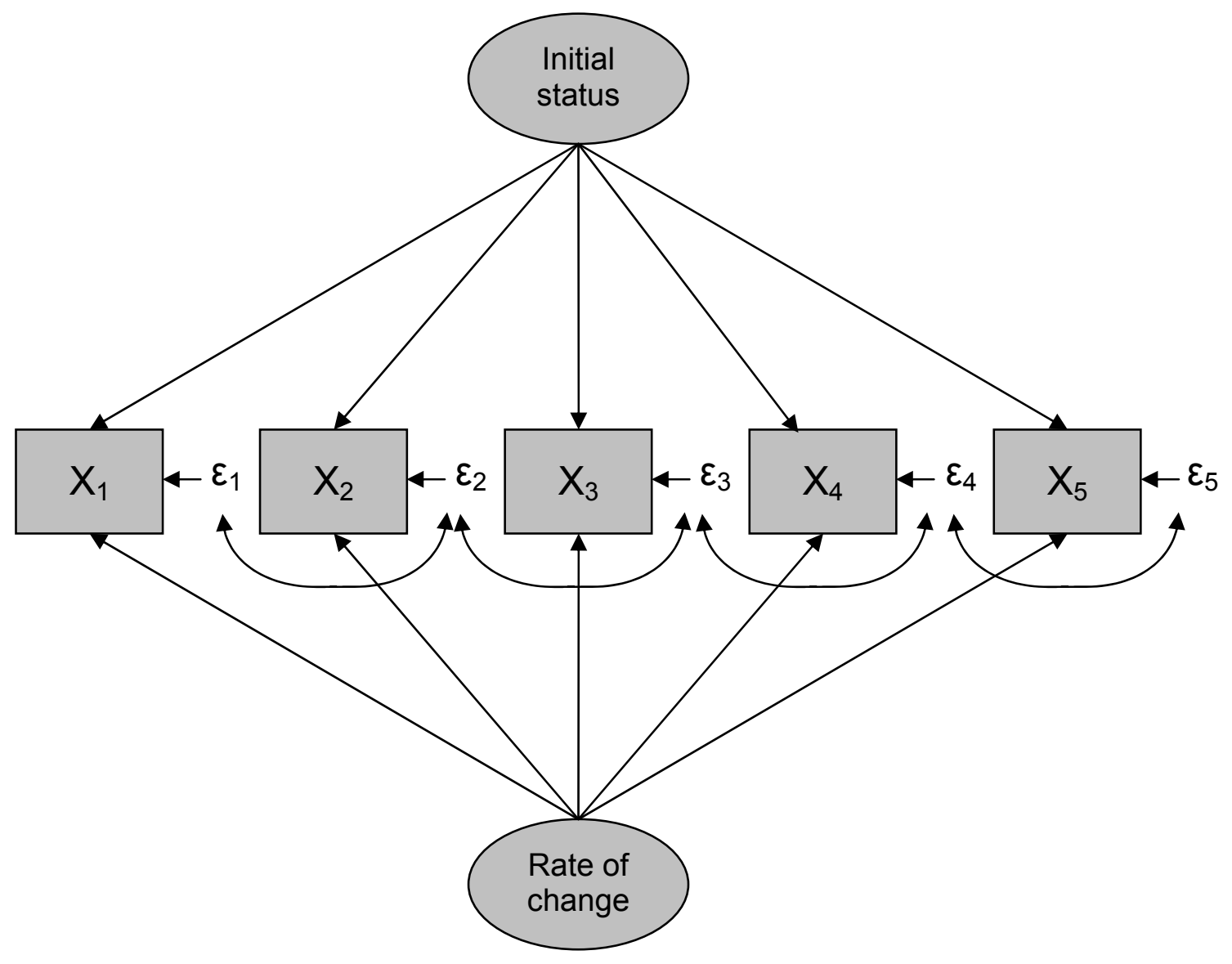


Figure 7: Two hazard functions for attendees and nonattendees of a leadership development program (Smith \& Tonidandel, 2003)

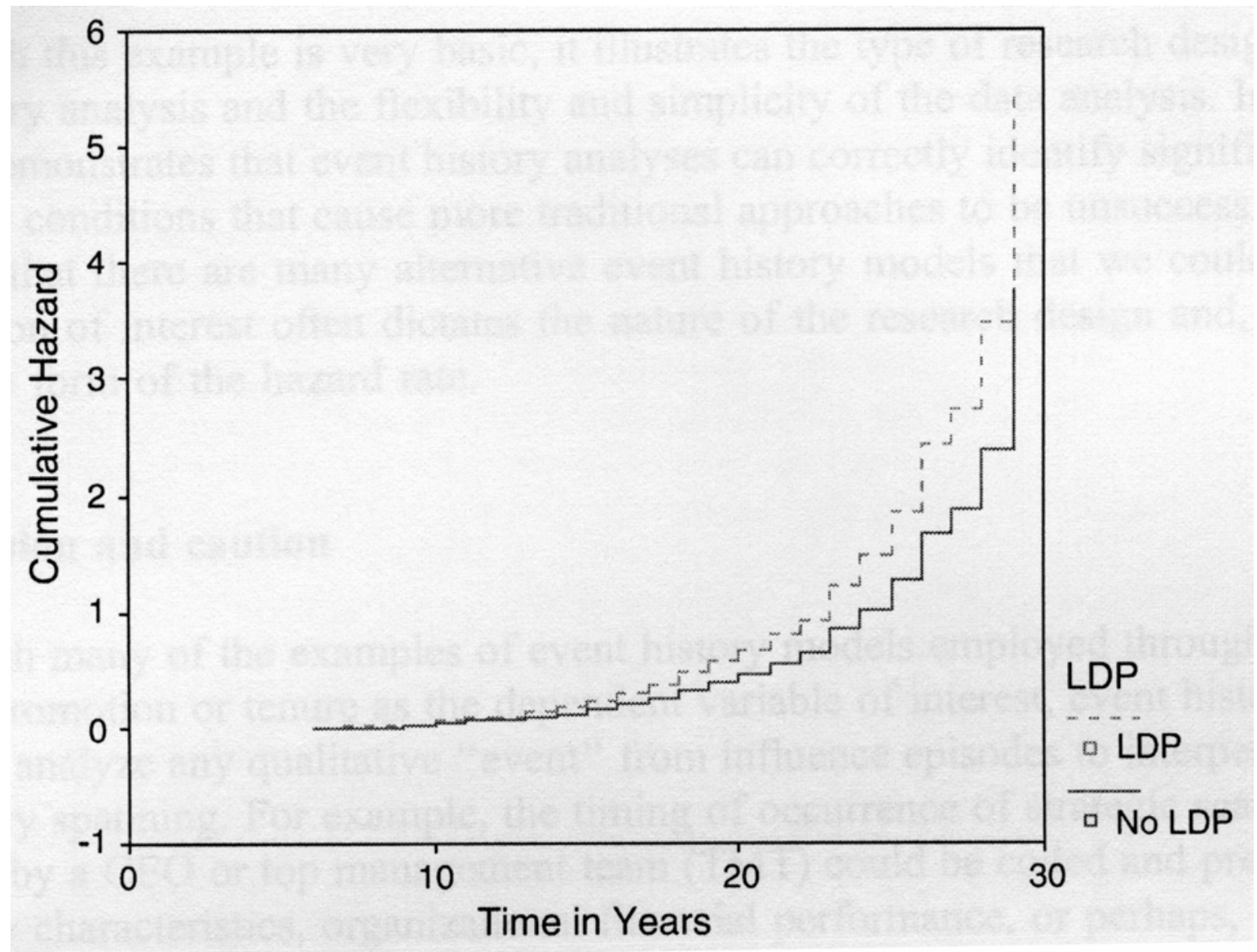


Bio-information

Robert A. Roe is Professor of Organizational Theory and Organizational Behavior at the Universiteit Maastricht. He has published on motivation, competence and performance, and HRM architectures. In his current work the emphasis is on the relationship between on organizational behavior and the informal organization. He is also studying conceptual and methodological issues in organizational research. 